Archimer, archive institutionnelle de l'Ifremer August-October 2009, Volume 62, Issues 2-3, Pages http://www.ifremer.fr/docelec/ 124-134 http://dx.doi.org/10.1016/j.seares.2009.02.006

(c) 2009 Elsevier B.V. All rights reserved.

\title{
A dynamic and mechanistic model of PCB bioaccumulation in the European hake (Merluccius merluccius)
}

\author{
Xavier Bodiguel ${ }^{\mathrm{a}, \mathrm{c}}$, Olivier Maury ${ }^{\mathrm{b}}$, Capucine Mellon-Duval ${ }^{\mathrm{c}}$, François Roupsard ${ }^{\mathrm{a}}$, Anne-Marie Le \\ Guellec $^{\mathrm{a}}$ and Véronique Loizeau ${ }^{\mathrm{a},{ }^{*}}$
}

\footnotetext{
a IFREMER, Département de Biogéochimie et Ecotoxicologie, Technopôle Brest-Iroise, Pointe du Diable, BP70, 29280 Plouzané, France

${ }^{b}$ IRD, Research Unit Thetis (UR109) CRH (Centre de Recherches Halieutiques Méditerranéennes et Tropicales), bd. J. Monnet BP171, 34203 Sète Cedex, France

${ }^{c}$ IFREMER, Département Halieutique Mediterranéen et Tropical, bd. J. Monnet BP171, 34203 Sète Cedex, France
}

\author{
*: Corresponding author : V. Loizeau, Tel.: +33 2982246 79; fax: +33 2982245 48, email address : \\ vloizeau@ifremer.fr
}

\begin{abstract}
:
Bioaccumulation is difficult to document because responses differ among chemical compounds, with environmental conditions, and physiological processes characteristic of each species. We use a mechanistic model, based on the Dynamic Energy Budget (DEB) theory, to take into account this complexity and study factors impacting accumulation of organic pollutants in fish through ontogeny. The bioaccumulation model proposed is a comprehensive approach that relates evolution of hake PCB contamination to physiological information about the fish, such as diet, metabolism, reserve and reproduction status. The species studied is the European hake (Merluccius merluccius, L. 1758). The model is applied to study the total concentration and the lipid normalised concentration of 4 PCB congeners in male and female hakes from the Gulf of Lions (NW Mediterranean sea) and the Bay of Biscay (NE Atlantic ocean). Outputs of the model compare consistently to measurements over the life span of fish. Simulation results clearly demonstrate the relative effects of food contamination, growth and reproduction on the PCB bioaccumulation in hake. The same species living in different habitats and exposed to different $\mathrm{PCB}$ prey concentrations exhibit marked difference in the body accumulation of PCBs. At the adult stage, female hakes have a lower PCB concentration compared to males for a given length. We successfully simulated these sex-specific PCB concentrations by considering two mechanisms: a higher energy allocation to growth for females and a transfer of PCBs from the female to its eggs when allocating lipids from reserve to eggs. Finally, by its mechanistic description of physiological processes, the model is relevant for other species and sets the stage for a mechanistic understanding of toxicity and ecological effects of organic contaminants in marine organisms.
\end{abstract}

Keywords: Merluccius merluccius; Demersal fish; Polychlorinated biphenyls (PCB); Bioaccumulation model; Bioenergetic; Dynamic Energy Budget (DEB) 


\section{Introduction}

Assessment of bioaccumulation and effects of pollutants in marine species is a fundamental step for environmental management. The development of a methodological framework for assessing bioaccumulation is therefore essential for the scientific evaluation of risks that chemicals may pose to the environment and by enlargement to humans. However, in the case of organic contaminants (OCs), bioaccumulation is difficult to document because responses differ among chemical compounds, with environmental conditions, and physiological processes characteristic of each species (Gobas, 1993; Connoly and Glaser, 2002). In early empirical approaches, the quantification of the bioaccumulation phenomena was deduced from concentrations in the organism (e.g. fish) and concentration of their prey and in water, to calculate bioaccumulation and bioconcentration factors (BAF and BCF). However, interpreting bioaccumulation data reveals difficulties related to the contaminant dynamics, possible changes in the environment (temperature, trophic conditions, prey contamination levels) and interactions with the physiology of animals.(Mackay and Fraser, 2000). To improve those tools, it is important to better characterize the dominant underlying processes driving the bioaccumulation phenomenon. Physiological-based models, (Norstrom et al., 1976; Gobas, 1993; Loizeau et al., 2001) take into account some of these processes. Gobas (1993) consider for example that contaminants may be taken up from food and from seawater by transfer through the gills, and lost by fecal egestion, metabolic degradation, and again, by transfer through the gills. Contaminant dilution resulting from growth was also considered as a pseudo-elimination process. These studies assume implicitly steady-state conditions for the physiological processes in the organism. But the kinetics and concentrations of the xenobiotic are affected by the changing physiological condition of fish. Consequently, these models do not always fit well the data, especially in conditions where the physiological state (ie. size, energy reserve and reproductive cycle) of the organism is changing (van Haren et al., 1994). Moreover, their lack of explicit physiological formulation make impossible a mechanistic understanding of the toxic effects of contaminants on organism physiology. Unifying concepts are needed to better tie together such complexities (Connolly and Glaser, 2002).

The uptake/elimination model proposed by Kooijman and Van Haren (1990) for organic contaminants such as PAHs (Polycyclic Aromatic Hydrocarbons) and PCBs (PolyChlorinated Biphenyls) has been designed to account for changes in the physiological conditions of the organism. It is based on the Dynamic Energy Budget (DEB) theory (Kooijman, 2000) which describes mechanistically growth, reserve dynamics and reproduction as a function of body size. Such a model is presented below for fish. The purpose of this paper is to test the applicability to fish of the DEB-based model to assess uptake-excretion kinetics for OCs by taking example of PCBs bioaccumulation in the European hake (Merluccius merluccius L. 1758). These contaminants are considered among the most dangerous pollutants because of their toxicity (Ahlborg and Hanberg, 1994; Loonen et al., 1996), stability, long biological halflife, and high liposolubility. They may also be bioaccumulated and biomagnified along food chains involving a wide range of trophic levels, with a potential risk for high trophic level predators (Borga et al., 2001; Hoekstra et al., 2003; Nfon and Cousins, 2006). Having a high trophic level (Ferraton et al., 2007), the European hake is exposed to the bioaccumulation of these organic compounds (Bodiguel et al., 2008). The model was built by coupling a PCB kinetic model through an organism to the standard DEB model. It was calibrated and tested on field data from the Gulf of Lions (Mediterranean sea) and the Bay of Biscay (Atlantic ocean). DEB parameters were estimated with field and experimental data or found in literature. In the model, we took into account contaminant uptake from food, contaminant losses due to spawning and we assessed the influence of physiological variables, such as body size and lipid content on PCB kinetics. Moreover, biotransformation of organic xenobiotics can affect elimination kinetics. But biotransformation increases the complexity of 
the analysis of the already complicated toxico-kinetic studies. Therefore, to simplify the analysis, we studied toxico-kinetics without biotransformation.Concerning PCBs, this phenomenon is negligible because of the high stability of these compounds. We also assumed that the physiological condition is not affected by the compounds although, one of the major interest of the DEB-based model is to offer a useful basis to describe such effects.

\section{Method}

\subsection{Sampling and chemical analysis}

The study areas are the Gulf of Lions, and the northern part of the Bay of Biscay, two regions off the French coasts (Fig. 1). The Gulf of Lions, situated in the NW Mediterranean, is one of most important continental shelf in the Mediterranean sea (Roussiez et al., 2005). It receives high freshwater discharges from the Rhône River watershed, which drains heavily industrialized regions of southern France. The Bay of Biscay, situated in the NE Atlantic, receives freshwater discharges from the Loire River, in western France. Hakes and its various preys were caught during bottom-trawl cruises, on the continental shelves (between 50 and 120 meters depth), in spring 2001, spring 2002 and autumn 2002 in the Bay of Biscay, and in spring 2004 and autumn 2004 in the Gulf of Lions. Largest specimens were caught on the edge of the continental shelf by gillnets, in autumn 2006 in the Gulf of Lions. A total of 202 hakes with total length (L) from 7 to $70 \mathrm{~cm}$ and 59 prey pools (sardines, anchovies, pouts, blue whitings, horse mackerels, gobiids, shrimps and zooplankton) were sampled for organic contaminant analysis. Fish were primarily pre-treated in the laboratory for total body weight, total length and macroscopic sex determination for hakes.

Chemical analysis have been described previously (Bodiguel et al., 2008) and are summarized below. The various biological species were solvent extracted using Soxtec apparatus. For samples from the gulf of Lions, extracts were weighed to give the amount of extractible material and thus a rough estimation of the total fat content. Appropriate clean-up of the extracts was then performed before the final instrumental analysis by gas chromatography with electron capture detector, on a HP 5890 series II equipped with a CPSil19 capillary column following optimized conditions described by Jaouen-Madoulet (2000). PCBs were quantified individually using a standard solution. Finally, concentrations of the different $\mathrm{PCB}$ congeners are available for each prey pool and at the individual level for hakes, for both sexes in the Gulf of Lions but without sex distinction in the Bay of Biscay. 4 PCB congeners described as few metabolisable were chosen because of different chlorination levels, two penta-chlorinated biphenyls: CBs 101 and 118, one hexa-chlorinated biphenyl: CB153, and one hepta-chlorinated biphenyl: CB180.

\subsection{Model structure}

Our bioenergetic approach is based on a mechanistic model, the DEB theory (Kooijman, 2000). It describes the acquisition and expenditures of energy in an organism, and the consequences for physiological organisation throughout its life cycle, in a potentially variable environment. A kinetic model of PCBs was then built, coupled to the bioenergetic one. It integrates the effects of growth and incorporates the chemical affinity of PCBs to reserve lipids. It is applied by taking the example of bioaccumulation of 4 PCB congeners (CBs) in the European hake (Merluccius merluccius, L.) from the Gulf of Lions (Mediterranean sea) and the northern part of the Bay of Biscay (Atlantic ocean). The 4 CBs were chosen among the seven indicators currently measured in pollution monitoring programs: CB101 $\left(2,2^{\prime}, 4,5,5\right.$ 'pentachlobiphenyl), CB118 (2,3',4,4',5-pentachlobiphenyl), $\quad$ CB153 $\quad\left(2,2^{\prime}, 4,4,, 5,5^{\prime}-\right.$ 
hexachlobiphenyl) and CB180 (2,2',3,4,4',5,5'-heptachlobiphenyl). They describe a large range of chlorination (from 5 to 8 chlorine molecules on the biphenyl core).

\subsubsection{DEB growth model}

DEB models are based on simple assumptions to describe the rates at which individual organisms assimilate and utilize energy from food, for maintenance, growth, reproduction and development (Fig.2). These rates depend on the state of the organism (size, sex, maturity status) and of its environment (food density, temperature). A conceptual introduction to the DEB theory can be found in Kooijman (2001) and in van der Meer (2006), a full description is given in Kooijman (2000). The dynamics of growth and reproduction are considered using a system of coupled differential equations for the three state variables: structural body volume $V\left(\mathrm{~cm}^{3}\right)$, energy reserve $E(\mathrm{~J})$, and energy allocated to development and reproduction $E_{R}(\mathrm{~J})$. Quantities are expressed per unit of volume with square brackets [] and per unit of biosurface area with braces \{\} . Rates have dots, indicating the dimension per time. According to the DEB theory, food uptake is proportional to the surface area of the structural body volume $\left(\mathrm{V}, \mathrm{cm}^{3}\right)$ and follows a type-II Holling functional response (Kooijman, 2000). The ingestion rate $\&$, $\left(\mathrm{J}^{-1}\right)$ is equal to:

$$
\text { \& }=\left\{\mathrm{R}_{\mathrm{x}}\right\} . f . V^{2 / 3}
$$

where $\left\{\&_{m}\right\}$ is the maximum surface area-specific ingestion rate $\left(\mathrm{J} \cdot \mathrm{cm}^{-2} \cdot \mathrm{d}^{-1}\right)$, calculated with maximum surface area-specific ingestion rate expressed in mass $\left\{\&_{X m}\right\}\left(\mathrm{g}_{\mathrm{c}} \mathrm{cm}^{-2} \cdot \mathrm{d}^{-1}\right)$ and the energy content of food $\left(\beta_{x}\right) . f$ is the scaled functional response, corresponding to $a$ function of food density (dimensionless).

An assimilation efficiency (ae), assumed constant, is applied to calculate the energy assimilation rate:

$$
\&_{A}=a e . \& \&_{X}=a e .\left\{\&_{X m}\right\} f V^{2 / 3}=\left\{\&_{A m}\right\} f V^{2 / 3}
$$

Assimilated energy is integrated in a reserve pool $E$, whose dynamics is given by the equation:

$$
\frac{d E}{d t}=\&_{A}-\&_{C}
$$

where $\left(J . \mathrm{d}^{-1}\right)$ denotes the energy utilization rate.

Stored energy is mobilized from reserve and is allocated to growth, maintenance and development or reproduction. A fixed fraction ( $k$ ) of energy used is allocated to somatic maintenance and growth while the remainder (1-K) is used for maturation/reproduction and maturity maintenance. Maintenance has priority over growth, so growth ceases when maintenance costs cannot be covered by reserve. From this energy allocation rule, it follows that growth investment is given by:

$$
\frac{d V}{d t}=\frac{\kappa\left[E_{G}\right]}{\left[E_{G}\right]}
$$

where $\left[\beta_{M}\right]$ is the maintenance cost $\left(\mathrm{J}_{\mathrm{cm}} \mathrm{cm}^{-3} \cdot \mathrm{d}^{-1}\right),\left[E_{G}\right]$ is the volume-specific cost for

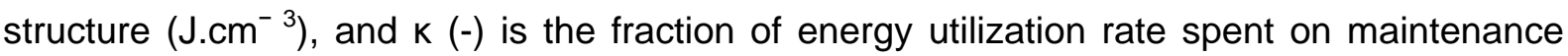
plus growth.

Kooijman (2000) derived the following equation of energy utilization from theoretical considerations: 


$$
\mathbb{R}_{\mathrm{C}}=\frac{[E]}{\left[E_{G}\right]+\kappa[E]}\left(\frac{\left[E_{G}\right]\left\{\&_{A m}\right\} V^{2 / 3}}{\left[E_{m}\right]}+\left[\boldsymbol{H}_{M}\right] V\right)
$$

where $[E]$ represents energy density $\left([E]=E / V, \mathrm{~J} \mathrm{~cm}^{-3}\right)$ and $\left[E_{m}\right]\left(\mathrm{J} \mathrm{cm}^{-3}\right)$ is the maximum energy density in the reserve compartment.

Juvenile development (increase of complexity) and adult state (energy investment for reproduction) correspond to two different stages in the individual life history. The transition between juveniles and adults occurs at a threshold value of the structural volume $V_{P}$ (volume at puberty). The length at $V_{P}$ is noted $L_{P}$. The evolution of the reproduction buffer at the adult stage is given by:

$$
\frac{d E_{R}}{d t}=\left((1-\kappa) \&-\frac{(1-\kappa)}{\kappa} V_{P}\left[\&_{M}\right]\right) \text { (6) }
$$

where $E_{R}$ represents the energy storage compartment allocated for reproduction.

During gamete emission, $E_{R}$ is emptied, with an efficiency $K_{\mathrm{R}} \cdot\left(1-\mathrm{K}_{\mathrm{R}}\right) E_{R}$ represents the gametogenesis cost. Total length $L(\mathrm{~cm})$ was obtained from body volume using:

$$
L=\frac{V^{1 / 3}}{\delta_{m}}
$$

where $\delta_{m}$ is the shape coefficient.

Fresh tissue mass $W(\mathrm{~g})$ was obtained by summing the 3 state variables $E(\mathrm{~J}), V\left(\mathrm{~cm}^{3}\right)$ and $E_{R}(\mathrm{~J})$, after conversion into fresh mass. A specific density $d$ of $1 \mathrm{~g} \cdot \mathrm{cm}^{-3}$ was used to convert somatic volume into mass (van der Veer, 2001):

$$
W_{\text {Total }}=d V+\left(\frac{\left(E+E_{R}\right)}{\beta_{E}}\right)
$$

where $\beta_{E}$ is the energy/mass converter of $E$ and $E_{R}$.

These two compartments are assumed to have the same energetic value (Kooijman, 2000).

$$
\frac{\left(E+E_{R}\right)}{\beta_{E}} \text { is the reserve weight }\left(W_{\text {Reserve }}\right) \text {. }
$$

DEB theory considers that reserve include each molecule that is immediately available to somatic synthesis, maintenance, development and reproduction, and that reserve can be classified into polysaccharides, lipids and proteins as ribosomal RNA (Kooijman 2000), with different proportions between the different species. In the case of fish, energetic reserve is described to be mainly constituted of lipids, especially neutral lipids (Tocher, 2003). To simplify the study, reserve weight has been considered to be equal to the weight of lipidic reserve $\left(W_{\text {Reserve }}=W_{\text {Lipid }}\right)$, and $\beta_{\mathrm{E}}$, the lipid energetic value.

Temperature has an effect on all physiological rates, here $\left\{p_{A m}{ }_{A m}\right.$ and $\left[p_{M}{ }_{M}\right]$. In the DEB theory, the Arrhenius description is used to describe the effect of temperature on metabolic rates:

$$
k(T)=k_{1}^{\&}(T) \exp \left\{\frac{T_{A}}{T_{1}}-\frac{T_{A}}{T}\right\}
$$

where $R^{\&}$ is a physiological rate, $T$ is ambient temperature $(K), T_{1}$ is a chosen reference temperature $(\mathrm{K})$ and $T_{\mathrm{A}}$ is a species-specific coefficient, the so-called Arrhenius temperature $(\mathrm{K})$. This Arrhenius temperature can be compared with the $Q_{10}$ values, according to:

$Q_{10}=\exp \left\{\frac{10 . T_{A}}{T . T_{1}}\right\}$ 


\subsubsection{Coupled bioaccumulation model}

In addition to DEB equations, a model of PCB kinetics has been established, coupled to the growth one, and apply with a same manner to the 4 studied congeners. In this model, we assume that fish contamination by PCBs is exclusively due to food consumption, which is a validated assumption in the case of highly hydrophobic compounds such as PCBs (Van Der Molen and Kooijman, 1996). It has been shown that absorption through the gill membrane affects the total body content to a much lesser extent (Russel et al., 1999; Leblanc, 2006). Uptake from the water is thus considered to be negligible in the model.

The rate at which contaminant is taken from food $\&_{p a}^{\&}\left(\mathrm{ng}^{\left.-\mathrm{d}^{-1}\right)}\right.$ integrates the lengthdependent hake diet and the PCB contamination of its different preys. It depends on the surface area specific ingestion rate $\left\{\mathbb{X}_{X m}\right\}\left(\mathrm{g} \cdot \mathrm{cm}^{-2} \cdot \mathrm{d}^{-1}\right)$, the functional response $f(-)$, the hake surface area $V^{2 / 3}\left(\mathrm{~cm}^{2}\right)$, the bolus contaminant concentration $C_{p}\left(\mathrm{ng} \cdot \mathrm{g}^{-1}\right)$ which is a forcing variable and a contaminant assimilation efficiency $a e_{P C B}(-)$ :

$\underset{p a}{\&}=\left\{\mathbb{X}_{X m}\right\} \cdot f \cdot V^{2 / 3} \cdot C_{p} \cdot a e_{P C B}$

Assimilated PCBs are stored in $W_{P C B}(\mathrm{ng})$.

PCBs are described as almost exclusively bound to reserve lipids in organisms, due to their lipophilic character (Van der Molen and Kooijman, 1996). As fish energetic reserve is mainly constituted of reserve lipids (Tocher, 2003), PCBs contained in $W_{P C B}$ are considered bound to storage lipids after assimilation. $\mathrm{PCB}$ concentration in reserve lipids $C L_{P C B}$ (ng. $\mathrm{g}^{-1}$ ) is given by:

$$
C L_{P C B}=\frac{W_{P C B}}{W_{\text {Reserve }}}
$$

Considering that PCBs cannot be metabolised by fish, the only PCB exit way is the reproduction, via gamete emission. It is considered that PCB affinity for gametes is different between male and female hake because of their gamete composition difference. For females, reserve lipids contained in $E_{R}$ are directly transferred into eggs with PCB associated. PCB loss during spawning $R_{P С B}(\mathrm{ng})$ is given by:

$$
R_{P C B}=\frac{W_{P C B}}{\left(E+E_{R}\right)} \cdot E_{R}
$$

For males, extracted energy from reserve lipid catabolism is used for spermatozoon synthesis (mostly proteic). Unbind PCBs during $\beta$-oxydation (production of ATP from lipids) bound again to the closest lipid reserve. For this reason, it is considered that PCBs associated to lipids stay in $W_{P C B}$ during spermatozoon synthesis. Consequently, $R_{P C B}=0$ for males. Finally, the PCB concentration in the whole individual $\left(C_{P C B}, \mathrm{ng} \cdot \mathrm{g}^{-1} \mathrm{~W}\right)$ is deduced by:

$$
C_{P C B}=\frac{W_{P C B}}{W_{\text {Total }}}
$$

\subsection{Parameter estimation}

\subsubsection{DEB parameter estimation}

Most of the DEB parameters were derived from environmental observations and experimental data conducted on the European hake. However the paucity of experimental data and the non directly measurable character of some specific DEB parameters led us to 
use a calibration procedure using data available in the literature for other fish of the Gadiform order like the cod (Gadus morhua).

\subsubsection{Shape coefficient}

Hake is considered to have an isomorphic growth and the same shape coefficient in the two study areas. It is assumed that reserve little contribute to total length, so that physical length quantifies structural length. The value of the shape coefficient is obtained by fitting a weightlength relationship of the type $W_{\text {Total }}=\mathrm{d}\left(\delta_{\mathrm{m}} \cdot \mathrm{L}\right)^{3}$, with $\mathrm{d}$ the density in $\mathrm{g} . \mathrm{cm}^{-3}$, to individuals smaller than the length at puberty $L_{p}$ (juveniles, without reproduction buffer). Here, the contribution of the reserve to the total weight is neglected. The shape coefficient was estimated to be 0.18 ( $n=2606$ juveniles from the Gulf of Lions, $p<0.001$ ).

\subsubsection{Temperature}

Bottom temperatures only are considered because hake spends most of its time near the bottom (Bozzano et al., 2005). The temperature is considered to be constant over the year under the mixed layer and equal to $12.8^{\circ} \mathrm{C}$ in the Gulf of Lions (Schroder et al., 2006), and to $12.5^{\circ} \mathrm{C}$ in the Bay of Biscay (Puillat and Lazure, 2004). We used the relation of Arrhenius to simulate effects of temperature on all the physiological rates. Since no Q10 estimates are available for hake, we took the value of $\mathrm{Q} 10$ estimated from juvenile cods $(\mathrm{Q} 10=2.35)$ by Peck et al. (2003) using respiration rate as a proxy for metabolism. This value correspond to an Arrhenius temperature of $6923^{\circ} \mathrm{K}$ (cf. eq. 10). The reference temperature was set to $12.5^{\circ} \mathrm{C}$.

\subsubsection{Feeding}

As hake is an opportunistic feeder (Mahe et al. 2007), it is difficult to estimate food ability in the environment. Nevertheless it is possible to evaluate an approximate functional response over the life of an animal by dividing the asymptotic length observed in a given environment $\left(L_{\text {inf }}\right)$ by the theoretical maximal length that an animal can attain if the food is not limited $\left(L_{\max }\right)$ : the largest fish ever observed (Kooijman, 2000). $L_{\max }$ is given at $140 \mathrm{~cm}$ for a female hake by Cohen et al. (1990). In our study areas, observed female $L_{\text {inf }}$ are $110 \mathrm{~cm}$ in the Bay of Biscay (de Pontual et al. 2006) and $100.7 \mathrm{~cm}$ in the Gulf of Lions (Recassens et al., 1998). Used functional responses for the present application are :

$f($ Bay of Biscay $)=110 / 140=0.786$, and $f$ (Gulf of Lions $)=100.7 / 140=0.719$

Values determined in experimental study are used to compute the rate of mass and energy intake. The ingestion rate value of hakes can be estimated from the study of Jolivet et al. (unpublished data). The ingested biomass of prey (sea bass Dicentrarchus labrax, given in excess) $\left\{\mathbb{X}_{X m}\right\}$ is $0.1312 \mathrm{~g} \cdot \mathrm{cm}^{-2} \cdot \mathrm{d}^{-1}$ at $12.5^{\circ} \mathrm{C}$, corresponding to a specific surface area ingestion rate $\left\{\beta_{x}\right\}$ of $735 \mathrm{~J} . \mathrm{cm}^{-2} \cdot \mathrm{d}^{-1}$ with a sea bass energy content $\left(\beta_{x}\right)$ of $5,6 \mathrm{~kJ} \mathrm{~g}^{-1}$ (Peres and Oliva-Teles, 2007). The specific surface area assimilation rate refers to the totality of ingested energy less the losses due to digestion and the faeces. Brett and Groves (1979) estimate that $20 \%$ of ingested energy is lost into faeces. $\left\{\alpha_{A m}\right\}$ is thus estimated assuming a fixed assimilation efficiency (ae) equal to 0.8: $\left\{\beta_{\mathrm{Am}}\right\}=735 * 0.8=588 \mathrm{~J} \cdot \mathrm{cm}^{-2} \cdot \mathrm{d}^{-1}$.

\subsubsection{Reproduction}

The length at puberty $L_{P}$ corresponds to the minimum fish size caught with gonads in development in each study area. It should be noticed that length at first allocation of energy to reproduction (i.e., length at puberty) is smaller than the length at first reproduction (i.e. length at maturity). The individual first fills the reproduction buffer and later converts it into 
gametes. This value does not affect growth but the amount of reserve allocated to reproduction before the first reproduction and therefore the first spawning season. In the Gulf of Lions, minimum hake sizes with gonads in development are given by Recasens et al. (1998): $30 \mathrm{~cm}$ for females and 22cm for males. In the bay of Biscay, Lucio et al. (2000) observed $40 \mathrm{~cm}$ for females and $30 \mathrm{~cm}$ for males.

Without data on hake reproductive investment, data on Gadus morua were used to estimate the $\mathrm{k}$ value. This species is indeed close to Merluccius in terms of taxonomic classification (both belong to the same Gadiform order), it has a metabolism relatively close to hake, and its biology has been very well studied. Jobling (1982) estimated the annual energy investment for reproduction of female cods from Faroe Islands and North Sea to 22\%. For this study, $k$ of female hake was then set to 0.78 .

Kooijman (2000) assumes that the overhead costs of female reproduction $\left(1-\kappa_{R}\right)$ are small: the reserve of the female are transformed into reserve of the offspring with a closely related chemical composition (high lipid content), so little chemical work is involved and $\kappa_{R}$ is set to 0.9. For males, this chemical composition is different, and mainly composed of proteins. In this case, $K_{R}$ is set to 0.7 . But this value has no influence on bioaccumulation because we consider that PCB losses during spermatogenesis are negligible. In the model, female spawning is triggered each year at a given date. For males, gamete emission time is described to cover the whole reproduction period of females for many fish. As the reproduction period of female hakes can cover all the year, the model consider a continuous emission of male gametes, all over the year.

\subsubsection{Calibration procedure}

Most of the specific DEB parameters cannot be measured directly (Van der Meer, 2006). This is the case for the maximum storage density $\left[E_{m}\right]$ (J.cm-3), the volume-specific cost for growth of structure ${ }^{\left[E_{G}\right]}(\mathrm{J} . \mathrm{cm}-3)$ and the volume-specific maintenance cost for structure [ J $_{\text {J }}$ ].cm-3). Kooijman et al., 2008 present a method to derive the value of those parameters using estimates of $\mathrm{K}_{1}\left\{\beta_{\mathrm{Am}}\right\}$, f, and quantities that are more easy to observe such as the volumetric length at first feeding $L b(\mathrm{~cm})$, the age at first feeding $a b(d)$, the volumetric ultimate length Linf $(\mathrm{cm})$ and the von Bertalanffy growth rate ${ }_{\mathrm{B}}^{\&}(\mathrm{~d}-1)$ or length at age data. The method permits to calculate compound parameters: $g$ the investment ratio, $k_{M}^{\&}$ the maintenance coefficient, and $\&$ the energy conductance. We used von Bertalanffy parameters of females in the Bay of Biscay to calibrate parameter values. In a second step, DEB parameters $\left({ }^{\left[E_{m}\right]},\left[E_{G}\right]\right.$ and $\left[\beta_{M}\right]$ ) have been calculated using equations proper to the DEB theory:

$\left[E_{m}\right]=\left\{\beta_{A m}\right\} / \&$.

$\left[E_{G}\right]=\left[E_{m}\right] . \kappa . g$

$\left[R_{M}\right]=k_{M}^{\&} .\left[E_{G}\right]$

"Easy to observe quantities" were taken in the literature describing larvae and female hakes from the Bay of Biscay. Volumetric lengths $L_{b}$ and $L_{\text {inf }}$ are obtained by dividing the total length by the shape coefficient. Due to the specific shape of the hake larvae a specific larvae shape coefficient was estimated for the calculation of $L_{b}$. In fact, larvae are more spherical than a juvenile or a adult hake (Bjelland et al., 2006). Without data on weight-at -length larvae, its shape was assimilated as a sphere, corresponding to a shape coefficient of 0.8 . Parameter values are given in Table 1. 


\subsubsection{Sexual dimorphism}

Male and female hakes exhibit growth dimorphism, with a faster growth rate and a higher ultimate size for females (Aldebert and Recasens, 1996; Morales-Nin et al., 1998). Without evidence for metabolism difference between sexes, it was considered that the metabolism of a single species is the same for both sexes. It was therefore chosen to simulate growth differences between sexes with only a difference of reproduction investment (1- $\kappa)$. This choice permits to simplify the parameter estimation, and to give genericity to the model. For females, $(\kappa)$ was estimated at 0.78 with data on cod reproduction investment. For males, $\kappa$ was calibrated to best fit the lengths at age data from de Pontual et al. (2006) and MellonDuval (unpublished data, comm. pers.). It was estimated to be 0.58 .

\subsubsection{Energy/mass conversion}

An energy mass converter $\beta_{E}$ was used to estimate the weight of reserve. The energy/mass conversion was assumed to be a constant. The model considers that reserve are exclusively composed of lipids. The lipid energetic value used in this study was set to $37 \mathrm{~kJ}^{-1} \mathrm{~g}^{-1}$ (Anon., 2003).

\subsection{Estimation of toxicokinetic parameters}

\subsubsection{PCB concentrations in the diet}

A special attention was devoted to describe PCB concentrations in the hake diet. Detailed description of hake diet from Ferraton et al. (2007) on hakes $<25 \mathrm{~cm}$, and Mellon-Duval et al. (unpublished data, comm. pers.) on hakes $\geq 25 \mathrm{~cm}$, was used in the Gulf of Lions. Data from Guichet (1995) on evolution of hake diet during its life were used in the Bay of Biscay. In these studies, variations of diet were described per size class of $5 \mathrm{~cm}$ for hakes $<30 \mathrm{~cm}$, and $10 \mathrm{~cm}$ for hakes $\geq 30 \mathrm{~cm}$. Measurements of PCB concentrations were carried out on these preys, and for different prey sizes when possible. According to Mahe et al. (2007), it was considered that hakes prey on sizes smaller than half of its length. The PCB bolus concentration $C_{p}$ was calculated in each length class of hake using the formula:

$$
C_{p}=\sum_{i=1}^{n}\left(C_{p i} * F_{i}\right)
$$

Where $C_{p i}$ is the PCB concentration in a given prey, and $F_{i}$, the mass percentage of this prey in the bolus content.

\subsubsection{Gut transfer}

Studies indicate that the assimilation efficiency of hydrophobic contaminants is closely linked to the digestion of the associated food (Gobas et al., 1993; Penry, 1998;Drouillard and Norstrom, 2000). These studies are relevant for hake because the mechanisms of uptake can be applied generally across species (Standaert, 1988). For the growth model, we considered a food assimilation efficiency of 0.8 . We consider that the PCB assimilation efficiency is the same $\left(a e_{P C B}=0.8\right)$, which is in accordance with Madenjian et al. (2000) who estimated PCB assimilation rate by trouts from the Great Lakes to be $81 \%$.

\subsection{Sensitivity analysis}

A simple sensitivity analysis was carried out to assess the influence of the main parameters on the model predictions. For both the growth model and the coupled bioaccumulation model, $a+10 \%$ and $-10 \%$ of each parameter value was applied to assess their individual influence on the total wet weight and the total CB153 concentration respectively. In both case, a sensitivity index $(S I)$ was calculated using the following formula: 


$$
S I=\frac{1}{n} \sum_{t=1}^{n} \frac{\left|W_{t}^{1}-W_{t}^{0}\right|}{W_{t}^{0}} * 100
$$

where $n$ is the number of simulated days, $W_{t}^{0}$ is the Total wet weight predicted with the standard simulation at time $t$, and $W_{t}^{1}$ is the Total wet weight predicted with the new parameter value at time $t$. The $S I$ value was calculated for both Mediterranean and Bay of Biscay models and both sexes.

\section{Results}

The model was applied to 4 PCB congeners, which are described as few metabolisable, the CBs 101, 118, 153, and 180, in two study areas of the French coast, the Gulf of Lions (N.W. Mediterranean) and the Bay of Biscay (Atlantic Ocean), represented on the Figure 1. These two sites differ by their environmental conditions (temperature, food density, PCB prey concentrations).

\subsection{Growth}

DEB model predictions applied in both study sites are presented in Figure 3, and compared to the Von Bertalanffy growth curves. Growth is presented for both sexes for a period of 10 years corresponding to the life expectation of hakes. In the Bay of Biscay, the growth of females is accurately predicted by the DEB model, with a similar growth rate and a similar ultimate size of $110 \mathrm{~cm}$. A deviation between the DEB model and the Von Bertalanffy curve is observable for males, especially the first years. Although the model underestimates male growth rate, the male ultimate size is well reproduced, with $80 \mathrm{~cm}$. In the Gulf of Lions, predictions of both male and female growth are accurately predicted by the model. Modeled ultimate sizes are $72.8 \mathrm{~cm}$ for males and $100.7 \mathrm{~cm}$ for females. These smaller ultimate sizes in the Gulf of Lions are due to the lower functional response (less food) than in Bay of Biscay. No difference between predicted and measured male growth is observed in the Gulf of Lions. The DEB model describes reserve dynamic in organisms over time. As fish reserve is mainly constituted of neutral lipids, their quantity can be estimated along the hake life. In the case of the Gulf of Lions, predicted lipid content can be compared to measurements (Fig. 4). Results are in the same order of magnitude than measurements, except for young hakes of undetermined sex and females larger than $50 \mathrm{~cm}$, where simulations overestimate lipid contents.

Sensitivity analysis show that the parameters governing food consumption, (i.e. $f$ and $\left\{\beta_{A m}\right\}$ ) and $\kappa$ have the most important effect on growth. An increase or a decrease of $10 \%$ of $f$, $\left\{\& \alpha_{m}\right\}$ and $\mathrm{k}$ yielded a mean variation of 25 to $33 \%$ of the mean wet weight (Fig. 5). To a lesser extend, an increase or a decrease of $10 \%$ of $\left[\mathrm{E}_{\mathrm{G}}\right]$ and $\left[\beta_{\mathrm{M}}\right]$ values caused a mean variation of 12 to $16 \%$ of the mean wet weight. Finally, our analysis show that parameters $\left[E_{m}\right]$ and $\beta_{E}$ have a weak effect on the predicted total wet weight. An increase or a decrease of $10 \%$ of their value caused a mean variation of 0 to $1 \%$ of the mean wet weight.

\subsection{PCB bioaccumulation}

Reconstitution of mean prey concentrations for the 4 studied PCB congeners is presented in Figure 6. These results are used as forcing variables of the model. In both study areas, highest concentrations were found for the CB153, and to a lesser extend for the CB180. 
Lowest concentrations were measured for CB118 and CB101. For the 4 congeners, concentrations increase until hake length reaches $35 \mathrm{~cm}$ in the Bay of Biscay and $40 \mathrm{~cm}$ in the Gulf of Lions. For hakes $>35 \mathrm{~cm}$ in the Gulf of Lions, and $>40 \mathrm{~cm}$ in the Bay of Biscay, the bolus concentration decreases. Predicted and measured concentrations of the 4 studied PCB congeners are plotted in Figure 7. There is a significant variation of concentrations between the two studied sectors. Mediterranean hakes present higher concentrations for the 4 congeners, from 2 to 5 times higher than in the Atlantic. In all cases, predicted concentrations are in good agreement with measurements during the whole life of hakes. The main difference between modelled and measuring values occur for the CB101 in both sites: simulations overestimate concentrations for hakes $<25 \mathrm{~cm}$. From hake sizes of $25 \mathrm{~cm}$ in the Gulf of Lions, and $30 \mathrm{~cm}$ in the Bay of Biscay, total PCB concentration increases quickly. At the same length, simulated males exhibit higher concentrations than females. Female concentrations decrease suddenly during spawning (-60\% of the total concentration during the first spawning). In the model, the spawning period was imposed at a fixed date. However, Recasens et al. (1998) described a high variability of length at first maturity for hake females in the Gulf of Lion: between 30 and $50 \mathrm{~cm}$. Although length at first maturity (i.e. ability to reproduction) is smaller than length at first reproduction (i.e. gamete emission), length at first spawning is also variable in the environment. Scenarios of different size at first spawning were tested for females from the Gulf of Lions. Figure 8 presents simulations of the evolution of $\mathrm{CB} 153$ concentrations, with length at first spawning ranging from 38 to $53 \mathrm{~cm}$. Results indicate that when the size at first spawning is increased, the PCB looses during the first spawning are more important (from $-50 \%$ of the CB153 total concentration for a female with a first spawning at $38 \mathrm{~cm}$, to $-70 \%$ for a female with a first spawning at $53 \mathrm{~cm}$ ). In the Gulf of Lions, predicted PCB concentrations normalized to lipids were compared to measurements (figure 9). Despite that PCB levels normalized to lipids present a high variability, predicted concentrations are in the same order of magnitude than measurements. However, it has to be noted that simulated concentrations are underestimated for undetermined sex hakes and females larger than $50 \mathrm{~cm}$, due the overestimation of their lipid content. It is noteworthy that spawning has no effect on lipid normalised concentration, because the PCB concentration in eggs is simulated as the same than in lipid reserve.

Concerning bioaccumulation, the results of the sensitivity analysis conducted indicate that an increase or a decrease of $10 \%$ of PCB prey concentrations and PCB assimilation efficiency lead to a mean variation of $10 \%$ of the total CB153 concentration (Fig. 10). The influence of these parameters on the bioaccumulation model is moderate. A $10 \%$ increase or decrease of the DEB-specific parameters governing growth has different impact on the total PCB concentration. The sensitivity of the model to these parameters varies with the sex and geographic location considered. The parameters governing food consumption, (i.e. $f$ and $\left\{\alpha_{A m}\right\}$ ) and $\kappa$ have the most important effect on total PCB concentrations. These variations are explained by the influence of those parameters on growth rate, and then on the PCB prey concentration consumed, because prey concentration is directly linked to hake length. Finally, it should be noted that the $k$ value has a greater impact on lipid normalized concentrations due to its influence on the amount of lipids allocated to reproduction.

\section{Discussion}

\subsection{DEB growth model}

We applied the DEB theory (Kooijman, 2000) to describe biological functions influencing persistent organic pollutants bioaccumulation at the scale of the hake life cycle. It was applied in two coastal French sites, and for both sexes. It has been considered that physiological parameters were the same for the two populations. Predictions of the growth model are especially influenced by parameters governing food consumption, i.e. the 
functional response $f$, which is a function of food density, and $\left\{\beta_{A m}\right\}$, the maximum surface area assimilation rate estimated using growth experiments from Jolivet et al. (unpublished data) on Atlantic hakes. We used a mean value for $\left\{\beta_{A m}\right\}$ since it was not possible to estimate inter-individual variations with the data available. More experiments would be needed to confirm this value and estimate inter-individual variations. The functional response was approximated in each study area using the ratio between estimated ultimate and maximum size. The advantage of this method is to evaluate a mean food density during the life of the hake, without consideration of seasonal variations for which little information is available. However, it is likely that the functional response differs between juveniles and adults due to the probable higher mobility of adults and their capacity to eat bigger preys. Finally, this method appears to be useful to describe the functional response of fish when the main objective is to simulate food intake at the scale of the entire life cycle.

The growth model also provides the evolution of the lipid content in the organism by converting energy reserve into lipid mass. When compared to the data, estimated lipid content of hakes $<25 \mathrm{~cm}$ and $>50 \mathrm{~cm}$ is overestimated. This overestimation can be due to the fact that a part of analysed lipids, as membrane phospholipids, can not be regarded as reserve but as structure. Consequently, the total lipid content measured on fish can be higher than the modelled reserve lipid content. Analyse of the different lipid classes would provide a better estimation of the reserve lipid content. Moreover, the ontogenic variation in the hake feeding may affect the hake lipid content (Lloret et al., 2008). This potential phenomenon is not taken into account by the model.

With parameters governing food consumption, $\mathrm{k}$ is the most influential parameter on growth. Due to the difficulty of maintaining hakes in captivity, no experimental data on hake reproduction are available. The value of female $\mathrm{k}$ has been simply derived from experiments on cod, and simplistic reproduction rules were used. A better understanding of hake reproduction is therefore essential to a better description of this function in our model. It is for example known that hake is a batch spawner (Murua et al., 2006) but in the absence of data on the number and frequency of batches, the model simulates a single spawning date per year. Nevertheless, this simplification does not modify the global PCB budgets at the scale of the life cycle. The parameter $\mathrm{K}$ as been designed to simulate growth rate differences observed between males and females. Without biological information about the cause of the sexual dimorphism described between males and females (Aldebert and Recasens, 1996; Morales-Nin et al., 1998), it was arbitrarily chosen to simulate this difference using two different values of $\mathrm{K}$, considering that all other parameters do not change with sex. Again, experiments in controlled conditions would help to refine the parameterization of the model. Finally, the DEB growth model might appear to be over-parameterised. This is the cost to pay for a mechanistic description of the biological processes influencing bioaccumulation.

\subsection{DEB bioaccumulation model}

The model describes the evolution of food uptake, growth and reproduction that are the main biological factors influencing the bioaccumulation processes. For the bioaccumulation model, a special attention has been devoted to the description of the evolution of hake diet. Reconstitution of mean prey concentrations from our measurements as a function of hake length shows that mean prey concentrations increase until hake length reaches $40 \mathrm{~cm}$ in the Bay of Biscay and $35 \mathrm{~cm}$ in the Gulf of Lion. In both cases, this corresponds first to an evolution of the hake diet mostly based on crustaceans, to a diet mainly composed of fish which are more contaminated (Guichet, 1995; Ferraton et al., 2007). Secondly, the increase of prey length with hake length is also responsible of the increase of the PCB bolus concentration. For a given species, a bigger specimen is older, and has more bioaccumulated PCBs. The quick increase of the PCB bolus concentration from hakes of $20 \mathrm{~cm}$ length in the Gulf of Lions and $30 \mathrm{~cm}$ in the Bay of Biscay, is due to a diet mainly based 
on small pelagic adults (i.e. sardines and anchovies) that are more contaminated. The decrease of mean prey concentrations for hakes $>35 \mathrm{~cm}$ in the Gulf of Lions, and $>40 \mathrm{~cm}$ in the Bay of Biscay, is due to a change of hake preferential prey, shifting from small pelagic fish to bigger pelagic or demersal fish (less contaminated) like blue whiting or horse mackerel.

Despite that the estimated physiological parameters are sometimes poorly determined, the PCB bioaccumulation model was successfully applied in our study areas. It reproduces both the absolute levels and the variations of total fish concentrations and gives a roughly approximation of lipid normalized concentrations of 4 PCB congeners for both sexes. From hake sizes of $20 \mathrm{~cm}$ in the Gulf of Lions, and $30 \mathrm{~cm}$ in the Bay of Biscay, total PCB concentration increases quickly. This observation is the direct consequence of the fast increase of the PCB bolus concentration at these sizes. It shows the important influence of the diet on concentrations observed in hake and highlights that a diet rich in small pelagic fish like sardines and anchovies induces high contamination in hake in both Atlantic and Mediterranean. Growth rate variation between males and females allow a good representation of observed PCB concentration variations between sexes. This difference is first due to a different dilution by growth, and secondly, to the fact that at same length, males are older, and have bioaccumulated during a longer period. Moreover, female concentrations decrease suddenly during spawning, due to the loss of PCBs contain in eggs. This phenomenon is not observable for males, because gamete emission doesn't lead to loss of PCBs. Reproduction has therefore a great influence on PCB contamination levels in females, and contributes to the concentration difference observed between the 2 sexes from the first spawning. The model proposes a realistic simulation of PCB looses during spawning by the mobilisation and transfer of lipid reserve and PCB associated to reserve to eggs. As a high variability of length at first maturity is observed for females from the Gulf of Lions (Recasens et al., 1998), different sizes at first spawning have been tested. Outputs of the model indicate that the larger the size at first spawning, the higher the PCB looses during the first spawning. We suggest that the variation of size at first spawning can explain a part of the concentration variability of PCBs observed in the female hake population from the Gulf of Lions.

The successful reconstruction of PCB concentration evolution in hake during the life cycle confirms the robustness of the model based on the DEB theory as well as the assumptions concerning PCB bioaccumulation (exclusive lipid composition of fish reserve and link between PCBs and reserve lipids). The underestimation of PCB concentrations normalized to lipids results from an overestimation of lipid content. A better estimation of lipid content (see above) should allow a better representation of these concentrations. Organic contaminants studied here are highly hydrophobic. For studying water-soluble compounds, the uptake of contaminants through the gills would have to be considered explicitly. In this case, the-uptake-elimination rates could be considered to be proportional to the respiration rate, and the model should then incorporate this function. In the DEB theory, respiration corresponds to oxygen consumption. As respiration includes routine metabolic costs as well as costs of growth, DEB theory considers that respiration is proportional to assimilation, growth and dissipation processes. In addition in the case of more water-soluble compounds, the contaminant repartition between the aqueous fraction (here, the somatic compartment) and the non aqueous fraction (the lipid reserve compartment) would also have to be considered (Kooijman and van Haren, 1990). The contaminant repartition between phases could then be taken as proportional to the octanol/water partition coefficient $\left(\mathrm{k}_{\mathrm{ow}}\right)$.

\section{Conclusion}

The model presented effectively describes growth and accumulation of PCBs during the life cycle of both male and female hakes. It accounts for the effects of growth, physiological condition (i.e. proportion of reserve), and reproduction on observed concentrations in two 
hake populations. Levels and evolution of 4 PCB congeners concentrations are well reproduced in two study areas: the Gulf of Lions (Mediterranean sea) and the Bay of Biscay (Atlantic ocean). This suggests that the basic assumptions of the model are valid and that the approach is adapted to study the fate of contaminants in fish. Study of less lipophilic compounds can be envisioned with this approach, including the uptake of contaminants through the gills and the biotransformation processes. Finally, the internal consistency of the proposed model of organic contaminant bioaccumulation sets the stage for a mechanistic understanding of toxicity and ecological effects of organic contaminants in marine organisms. Some contaminants are considered to alter energy use by causing energy loss or poor energy management. Including those toxicity phenomenon into our bioaccumulation model would allow to model the effects of contaminants on physiological functions.

\section{Acknowledgments}

This work was partially funded by the Regional Council of Languedoc-Rousillon. Moreover, we would like to thank the crew of the IFREMER boats "L'Europe" and "Gwen-drez" for making the sampling possible. The authors are also grateful to Pierre Bodenes for drawing the map, Aurélie Jolivet for communicated her data, Bas Kooijman and the AquaDEB team (www.ifremer.fr/aquadeb/) for their assistance. 


\section{References}

Anonyme, 2003. Food energy-methods of analysis and conversion factors, Rome 2003. FAO, Food and Nutrition Paper 77.

Ahlborg, U.G., Hanberg, A., 1994. Toxic equivalency Factors for dioxon-like PCBs. Environ. Sci. Pollut. Res. Int. 1, 67-68.

Aldebert, Y., Recasens, L., 1996. Comparison of methods for stock assessment of European hake Merluccius merluccius in the Gulf of Lions (Northwestern mediterranean) Aquatic living ressources 9, 13-22.

Bjelland, R.M., Skiftesvik, A.B., 2006. Larval development in European hake (Merluccius merluccius L.) reared in a semi-intensive culture system. Aquaculture research $37,1117-$ 1129.

Bodiguel X., Tronczyński J., Loizeau V., Munschy C., Guiot N., Le Guellec A.M., Olivier N., Roupsard F., Mellon C., 2008. Classical and novel organohalogen compounds (PCBs and PBDEs) in hake (M. merluccius, L.) from Mediterranean and Atlantic coasts (France). Wit Transactions on Ecology and Environment 110, 157-166.

Borga, K., Gabrielsen, G.W., Skaare, J.U., 2001. Biomagnification of organochlorines along a Barents Sea food chain. Environ. Poll. 113, 187-198.

Bozzano, A., Sardà, F., Rios, J., 2005. Vertical distribution and feeding patterns of the juvenile European hake, Merluccius merluccius in the NW Mediterranean. Fisheries Research 73, 29-36.

Brett, J.R. and Groves, T.D.D., 1979. Physiological energetics. In: Hoar, W.S., Randall, D.J. and Brett, J.R., Editors, 1979. Fish Physiology 8, Academic Press, New York, 279-352.

Cohen, D. M., Inada, T., Iwamoto, T., and Scialabba, N., 1990. FAO species catalogue, 10. Gadiform fishes of the world (order Gadiformes). An annotated and illustrated catalogue of cods, hakes, grenadiers and other gadiform fishes known to date. FAO Fisheries Synopsis $10,442$.

Connolly, J.P. and Glaser, D., 2002. p.p'-DDE bioaccumulation in female sea lions of the California Channel Islands. Continental Shelf Research 22, 1059-1078.

de Pontual, H., Groison, A.L., Pineiro, C., Bertignac, M., 2006. Evidence of underestimation of European hake growth in the Bay of Biscay and the relationship with bias in the agreed ageing method. ICES JMS. 63, 1674-1681.

Drouillard, K.G., Norstrom, R.J., 2000. Dietary absorption efficiencies and toxicokinetics of polychlorinated biphenyls in ring doves following exposure to Aroclor (R) mixtures Environ. Toxicol. and Chem. 19, 2707-2714.

Ferraton, F., Harmelin-Vivien, M., Mellon-Duval, C., Souplet, A., 2007. Spatio-temporal variation in diet may affect condition and abundance of juvenile European hake in the Gulf of Lions (NW Mediterranean). Mar. Ecol. Prog. Ser. 337, 197-208. 
Gobas, F.A.P.C., 1993. A model for predicting the bioaccumulation of hydrophobic organic chemicals in aquatic food-webs: application to Lake Ontario. Ecol. Model. 69, 1-17.

Guichet, R., 1995. The diet of European hake (Merluccius merluccius) in the northern part of the Bay of Biscay. ICES J. Mar. Sci. 52, 21-31.

Hoekstra, P.F., O'Hara, T.M., Fisk, A.T., Borgå, K., Solomon, K.R., Muir, D.C.G., 2003. Trophic transfer of persistent organochlorine contaminants (OCs) within an Arctic marine food web from the southern Beaufort-Chukchi Seas. Environ. Pollut. 124, 509-522.

Holling, C. S., 1959. Some characteristics of simple types of predation and parasitism. Can. entomol. 91, 385-398.

Jobling, M., 1982. Food and growth relationship of the cod, Gadus Morhua L., with special reference to Balsfjorden, north Norway. J. Fish Biol. 21, 357-372.

Jolivet, A, de Pontual, H, Hervy, M., Paulet Y.M., Fablet, R. Towards domestication of European hake: relationships of growth with dietary and temperature. Submitted in Aquaculture.

Kooijman, S.A.L.M. and van Haren, R.J.F., 1990. Animal energy budgets affect kinetics of xenobiotics. Chemosphere 21, 681-693.

Kooijman, S.A.L.M., 2000. Dynamic Energy and Mass Budgets in Biological Systems. Cambridge University Press, Cambridge.

Kooijman, S.A.L.M., 2001. Quantitative aspects of metabolic organizations; a discussion of concepts. Phil. Trans. R. Soc. B 356, 331-349.

Kooijman, S.A.L.M., Sousa. T., Pecquerie L., van der Meer J. and Jager T., 2008. The estimation of DEB parameters, a practical guide. Biol. Rev. 83, pp. 533-552.

Leblanc, L.A., Buckel, J.A., Conover, D.O., Brownawell, B.J., 2006. Tests of bioaccumulation models for polychlorinated biphenyl compounds: A study of young-of-the-year bluefish in the Hudson River estuary, USA. Environmental Toxicology and Chemistry 25, 2067-2076.

Lloret, J., Demestre, M., Sanchez-Pardo, J., 2008. Lipid (energy) reserves of European hake (Merluccius merluccius) in the north-western Mediterranean. Vie et Milieu 58, 77-85.

Loizeau, V., Abarnou, A., Menesguen, A., 2001. A Model of PCB Bioaccumulation in the Sea Bass (Dicentrarchus labrax) Food Web from the Seine Estuary (Eastern English Channel). Mar. Poll. Bull. 43, 242-255.

Loonen, H., van de Guchte, C., Parsons, J.R., de Voogt, P., Govers, H.A.J., 1996. Ecological Hazard assessment of Dioxins : Hazards to organisms at different levels of aquatic food webs (fish-eating birds and mammals, fish and invertebrates). Sci. of Tot. Environ. 182, 93103.

Lucio, P., Murua, H. \& Santurtun, M., 2000. Growth and reproduction of hake (Merluccius merluccius) in the Bay of Biscay during the period 1996-1997. Ozeanografika 3, 325-354.

Madenjian C. P., O'Connor D.V., Nortrup D.A., 2000. A new approach toward evaluation of fish bioenergetics models. Can. J. Fish. Aquat. Sci. 57, 1025-1032. 
Mackay, D. and Fraser, A., 2002. Bioaccumulation of persistent organic chemicals: mechanisms and models. Environ. Pollut. 110, 375-391.

Mahe, K., Amara, R., Bryckaert, T., Kacher, M., Brylinski, J. M., 2007. Ontogenetic and spatial variation in the diet of hake (Merluccius merluccius) in the Bay of Biscay and the Celtic Sea. ICES J. Mar. Sci. 64, 1210-1219.

Mendes, E. and Gonzales, R.M., 1997. Seasonal changes in the chemical and lipid composition of the Southwest Atlantic hake (Merluccius hubbsi). Food chemistry 59, 213217.

Morales-Nin, B., Tores, G.J., Lombarte, A., Recasens, L., 1998. Otolith growth and age estimation in the European hake. J. of Fish Biol. 53, 1155-1168.

Murua, H., Lucio, P., Santurtun, M., and Motos, L., 2006. Seasonal variation in egg production and batch fecundity of European hake Merluccius merluccius (L.) in the Bay of Biscay. J. of Fish Biol. 69, 1309-1316.

Nfon, E., Cousins, I.T., 2006. Interpreting time trends and biomagnification of PCBs in the Baltic region using the equilibrium lipid partitioning approach. Environ. Poll. 144, 994-1000.

Norstrom, R.J., McKinnon, A.E. and De Freitas, A.S.W., 1976. A bioenergetics-based model for pollutant accumulation by fish: simulation of PCB and methylmercury residue levels in Ottawa River yellow perch (Perca flavescens), J. Fish. Res. Board Can. 33, 248-267.

Peck, M. A., Buckley J., Bengtson, D.A., 2003. Energy losses due to routine and feeding metabolism in young-of-the-year juvenile Atlantic cod (Gadus morhua). Can. J. Fish. Aquat. Sci. 60, 929-937.

Penry, D.L., 1998. Applications of efficiency measurements in bioaccumulation studies: Definitions, clarifications, and a critique of methods. Environ. Toxicol. Chem.17, 1633-1639.

Peres, H., Oliva-Teles, A., 2007. Effect of the dietary essential amino acid pattern on growth, feed utilization and nitrogen metabolism of European sea bass (Dicentrarchus labrax). Aquaculture 267, 119-128.

Puillat, I., Lazure, P., 2004. Hydrographical variability on the French continental shelf in the Bay of Biscay, during the 1990s. Cont. Shelf Res. 10, 1143-1163.

Recasens, L., Lombarte, A., Morales-Nin, B., Torres, G.J., 1998. Spatio-temporal variation in the population structure of the European hake in the NW Mediterranean. J. Fish. Biol. 53, 387-401.

Roussiez, V., Aloisi, J. C., Monaco, A., Ludwig, W., 2005.Early muddy deposits along the Gulf of Lions shoreline: A key for a better understanding of land-to-sea transfert of sediments and associated pollutant fluxes. Mar. Geol., 222-223, 345-358.

Russell, R.W., Gobas, F.A.P.C., and Haffner, G.D., 1999. Role of chemical and ecological factors in trophic transfer of organic chemicals in aquatic food webs. Environ. Toxicol. Chem. $18,1250-1257$. 
Schroder K, Gasparini GP, Tangherlini M, and Astraldi M., 2006. Deep and intermediate water in the western Mediterranean under the influence of the Eastern Mediterranean Transient. Geophysical Research Letters 33.

Standaert, F.G., 1988. Absorption and distribution of xenobiotics. Environmental Health Perspectives 77, 63-71.

Tocher, D. R., 2003. Metabolism and Functions of Lipids and Fatty Acids in Teleost Fish. Reviews in Fisheries Science 11, 107-184.

van der Meer, J., 2006. An introduction to Dynamic Energy Budget (DEB) models with special emphasis on parameter estimation. J. of Sea Res. 56, 85-102.

van der Veer, H. W., 2001. Intra and interspecies comparison of energy flow in North Atlantic flatfish species by means of dynamic energy budgets. J. of Sea Res. 45, 303-320.

van der Veer, H.W., Cardoso, J.F.M.F., van der Meer, J., 2006. The estimation of DEB parameters for various Northeast Atlantic bivalve species. J. of Sea Res. 56, 107-124.

van Haren, R.J.F., Schepers, H.E., Kooijman, S.A.L.M., 1994. Dynamic Energy Budgets affect kinetics of xenobiotics in the marine mussel Mytilus edulis. Chemosphere 29, 163-189. 
Table 1: List of DEB parameters. Rates are given at the reference temperature $T_{1}=285.5 \mathrm{~K}$ $\left(12.5^{\circ} \mathrm{C}\right)$. Lengths are expressed in total length $(\mathrm{cm})$. GoL, Gulf of Lion ; BoB, Bay of Biscay.

\begin{tabular}{|c|c|c|c|c|}
\hline Parameters & Symbol & Units & Value & Source \\
\hline Water temperature & $\mathrm{T}$ & ${ }^{\circ} \mathrm{K}$ & 283.5 & Puillat and Lazure, 2004 \\
\hline Arrhenius température & $\mathrm{T}_{\mathrm{A}}$ & ${ }^{\circ} \mathrm{K}$ & 6923 & after Peck et al., 2003 \\
\hline Shape coefficient & $\delta_{\mathrm{m}}$ & - & 0.18 & Ifremer Surveys \\
\hline \multirow[b]{2}{*}{ Functional response } & \multirow[b]{2}{*}{$f$} & - & $0.719(\mathrm{BoB})$ & after Recasens et al., 1998 \\
\hline & & - & $0.786(\mathrm{GoL})$ & after de Pontual et al., 2006 \\
\hline Max. surf. area-specific ingestion rate & $\left\{\mathrm{p}^{\prime} \mathrm{xm}\right\}$ & $\mathrm{J} \mathrm{cm} \mathrm{j}^{-2}$ & 735 & Jolivet et al. (unpub. data) \\
\hline Assimilation efficiency & ae & - & 0.8 & Brett and Groves, 1979 \\
\hline \multirow{4}{*}{ Fraction of $p_{c}$ spent on maint. plus growth } & \multirow{4}{*}{ к } & - & 0.78 (females) & Jobling, 1982 \\
\hline & & - & 0.58 (males) & calib. \\
\hline & & $\mathrm{cm}$ & 30 (females GoL) & Recasens et al., 1998 \\
\hline & & $\mathrm{cm}$ & 22 (males GoL) & Recasens et al., 1998 \\
\hline \multirow[t]{3}{*}{ Length at puberty } & \multirow[t]{3}{*}{$\mathrm{L}_{\mathrm{P}}$} & $\mathrm{cm}$ & 40 (females BoB) & Lucio et al., 2000 \\
\hline & & $\mathrm{cm}$ & 30 (males BoB) & Lucio et al., 2000 \\
\hline & & - & 40 (females) & Kooijman, 2000 \\
\hline Fraction of repro. energy fixed in gametes & $\kappa_{\mathrm{R}}$ & - & 0.7 (males) & estimated. \\
\hline Maximum storage density & {$\left[\mathrm{E}_{\mathrm{m}}\right]$} & $\mathrm{J} \mathrm{cm}^{-3}$ & 1505 & calib. \\
\hline Volume specific maintenance cost & {$\left[\mathrm{p}_{\mathrm{M}}\right]$} & $\mathrm{J} \mathrm{em}^{-3} \mathrm{~d}^{-1}$ & 18.15 & calib. \\
\hline Volume-specific cost for structure & {$\left[\mathrm{E}_{\mathrm{G}}\right]$} & $\mathrm{J} \mathrm{cm}^{-3}$ & 7563 & calib. \\
\hline Energy content of lipids & $\beta_{\mathrm{E}}$ & $\mathrm{Jg}^{-1}$ & 37000 & Anon., 2003 \\
\hline \multicolumn{5}{|l|}{ Parameters used for calibration } \\
\hline Ultimate length & $L_{i n f}$ & $\mathrm{~cm}$ & 110 & de Pontual et al., 2006 \\
\hline Length at first feeding & $L_{b}$ & $\mathrm{~cm}$ & 0.4 & Bjelland et al., 2006 \\
\hline Shape coefficient (larvae) & $\delta_{1}$ & - & 0.8 & after Bjelland et al., 2006 \\
\hline Age at first feeding & $a b$ & $\mathrm{D}$ & 4 & Bjelland et al., 2006 \\
\hline Von Bertalanffy growth rate & $r_{B}$ & - & 0.261 & de Pontual et al., 2006 \\
\hline
\end{tabular}




\section{Figures}

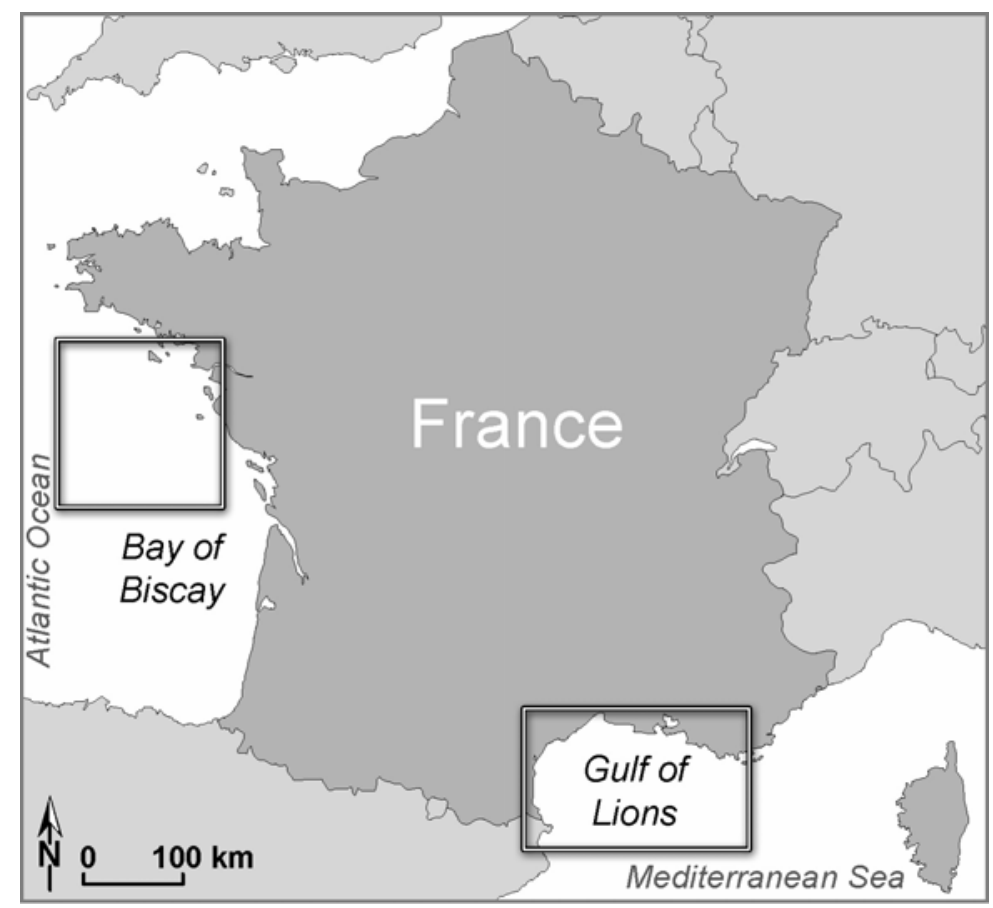

Figure 1: Map of the study area showing the two sampled sites: the Bay of Biscay and the Gulf of Lions

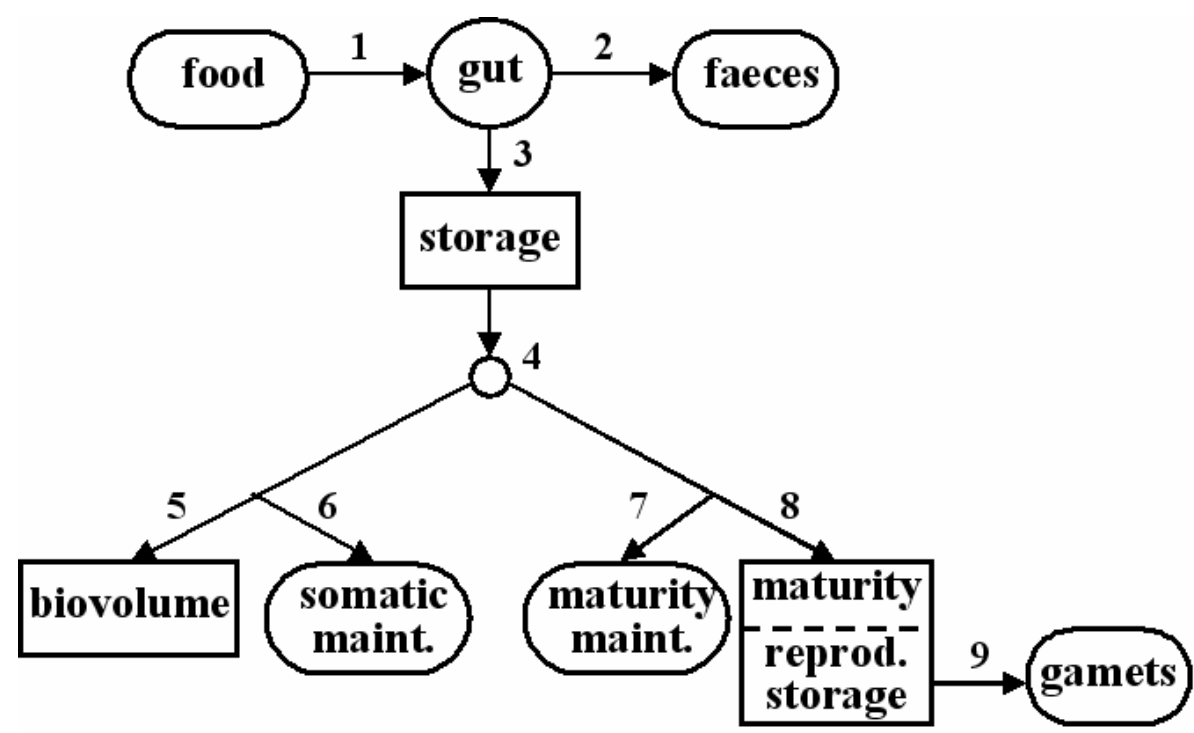

Figure 2. Energy flows through an organism in the DEB model, after Kooijman (2000). Rates: 1 ingestion (uptake), 2 defecation, 3 assimilation, 4 utilisation, 5 growth, 6 somatic maintenance, 7 maturation maintenance, 8 maturation, 9 reproduction. The rounded boxes indicate sources or sinks, the squares indicate state variables. 
a)

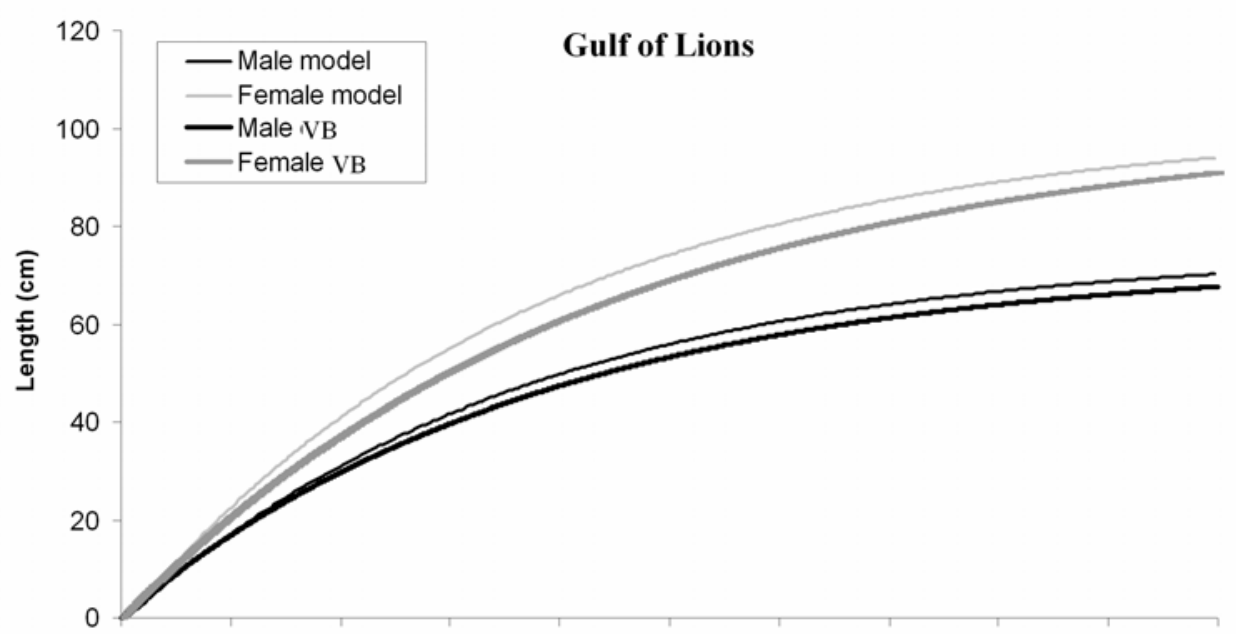

b)

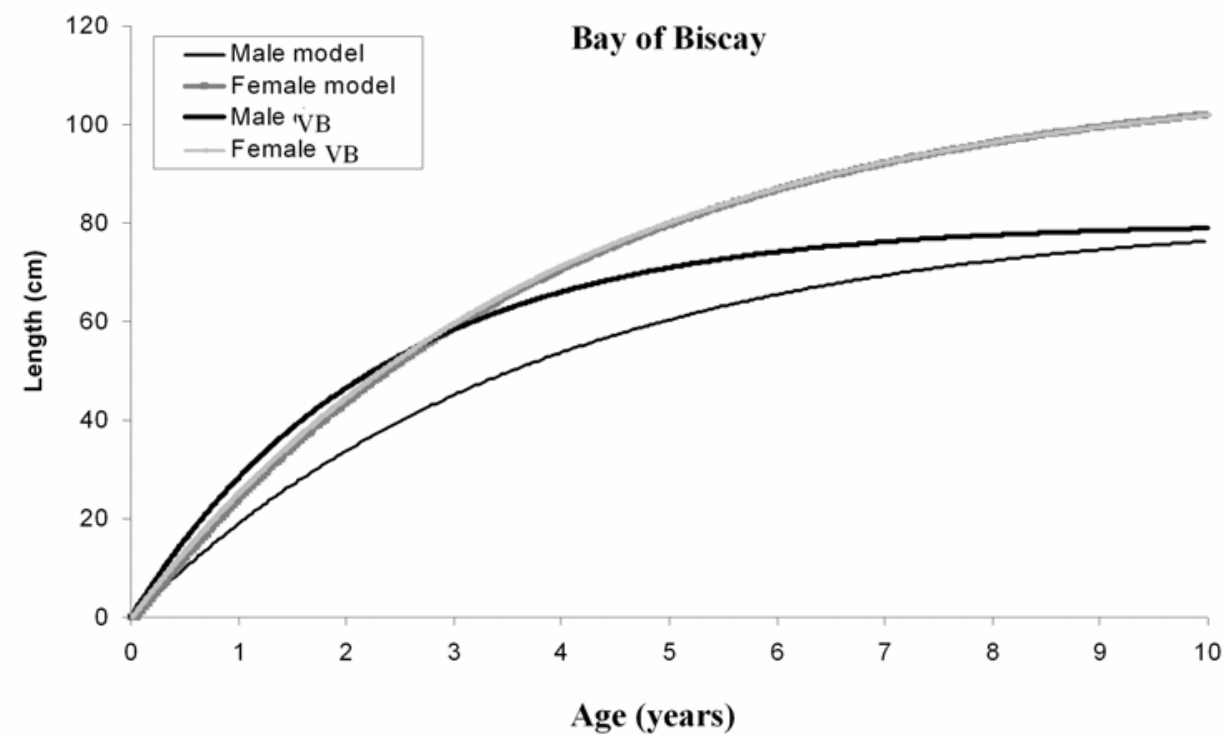

Figure 3: Simulated growth of female and male hake in a) the Gulf of Lions, and b) the Bay of Biscay, for a period of 10 years. Comparison with Von Bertalanffy (VB) growth curves proposed by Mellon-Duval (unpublished data, comm. pers.) in the Gulf of Lions, and de Pontual et al. (2006) in the Bay of Biscay. 


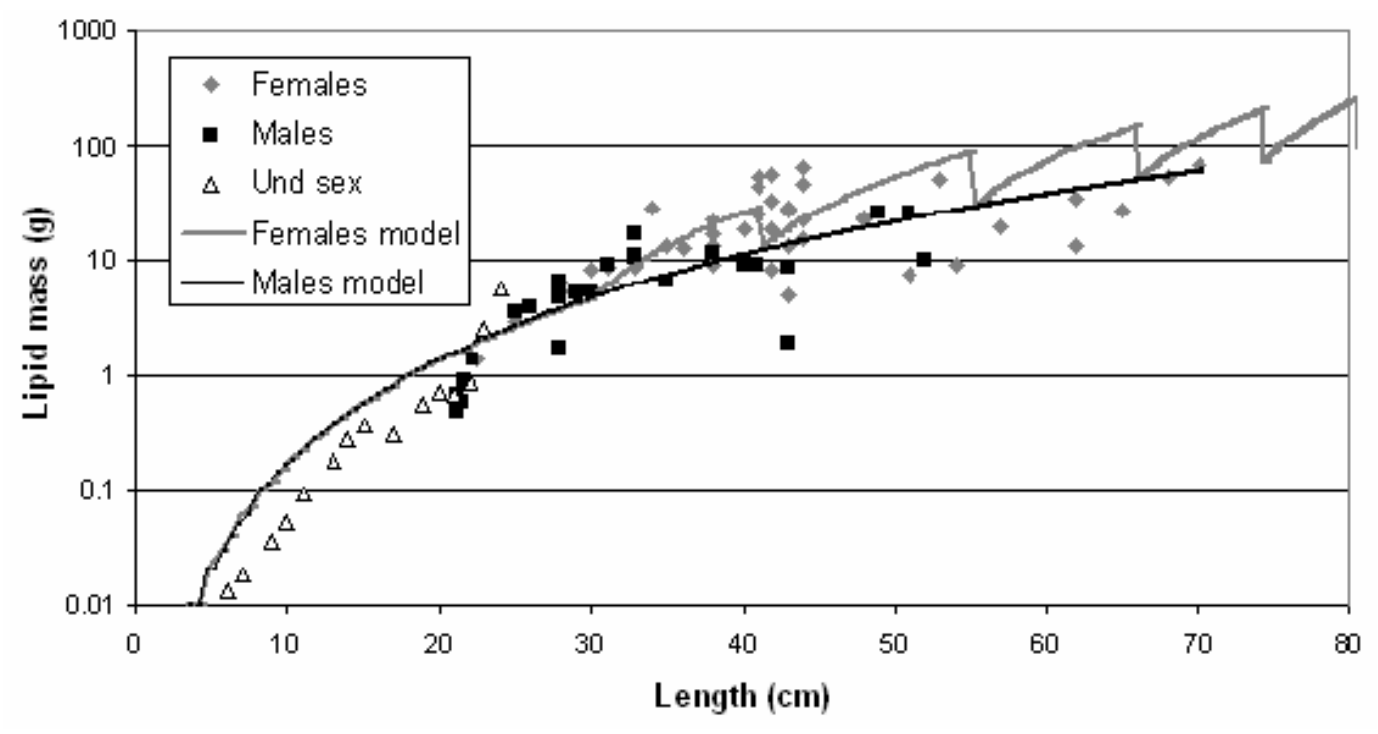

Figure 4 : Simulations of the evolution of the reserve lipid mass with a logarithmic scale as function of length for female (gray line) and male (black line) in the Gulf of Lions, for a period of 10 years. Data for undetermined sex (Und sex, black triangles), females (grey squares) and males (black squares) sampled in 2004 in the Gulf of Lions are represented. 


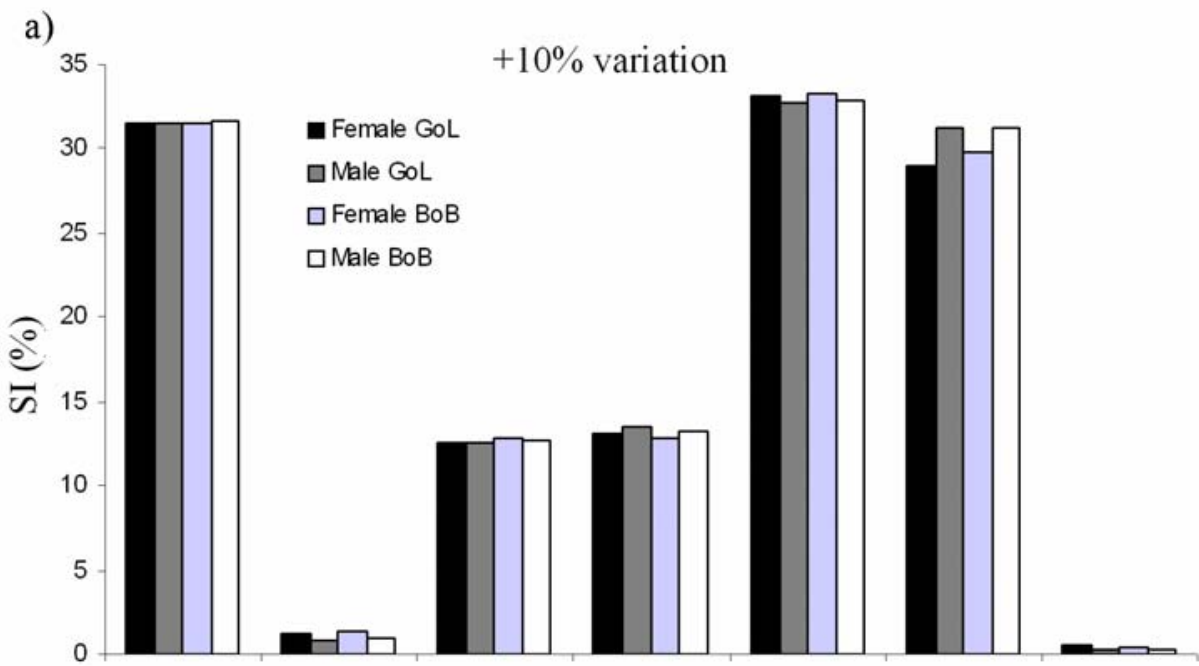

b)

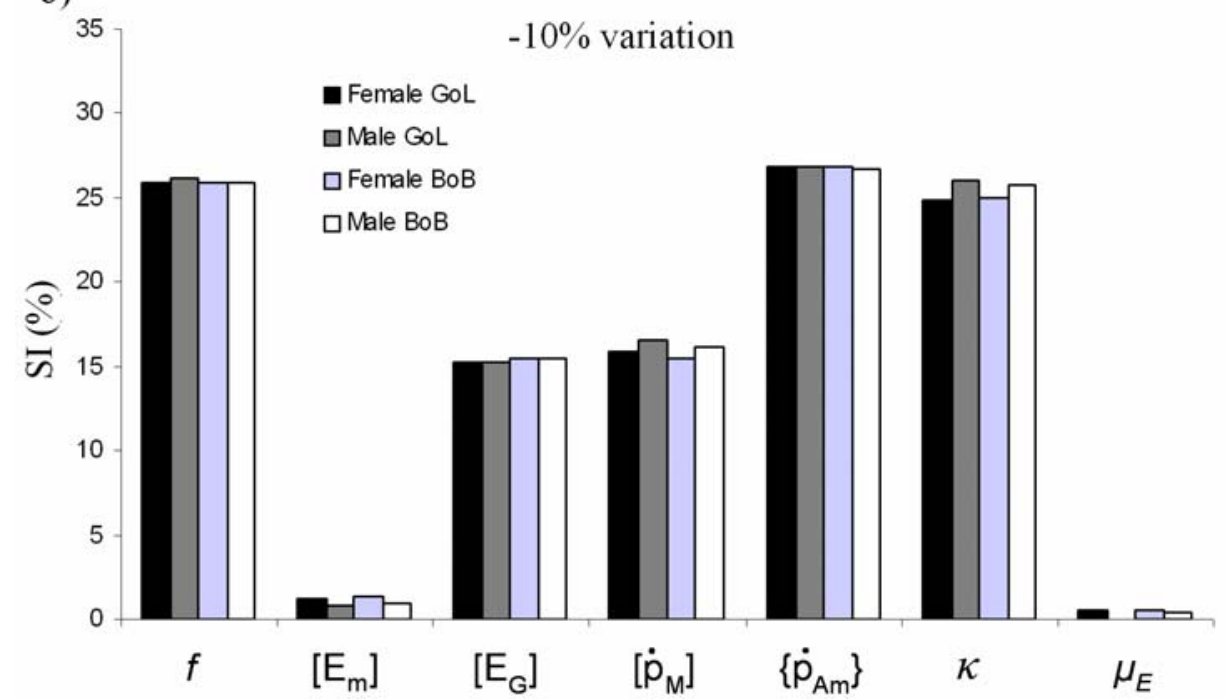

Figure 5: Sensitivity index (SI) on hake growth, computed for DEB parameters for both sexes in the Gulf of Lions (GoL) and the Bay of Biscay (BoB). a) effect of $+10 \%$ variation of parameter values, and $b$ ) effect of $-10 \%$ variation of parameter values. 
a)

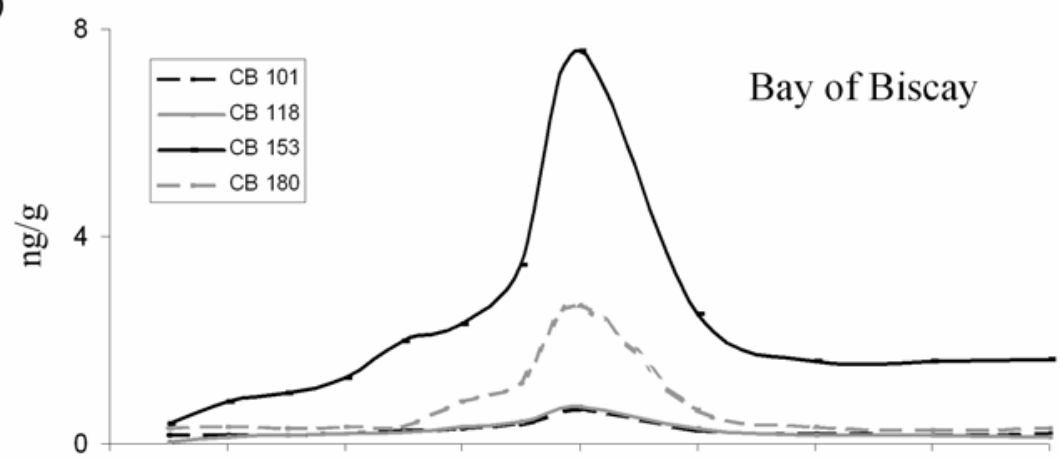

b)

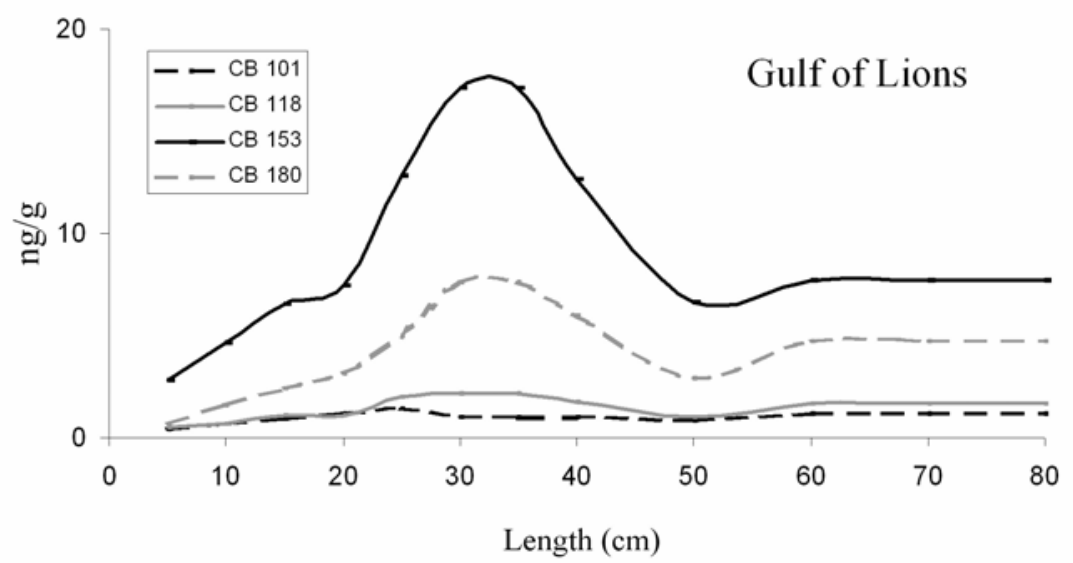

Figure 6: Evolution of the reconstituted bolus concentrations $\left(\mathrm{ng} \cdot \mathrm{g}^{-1}\right)$, as function of hake length (males and females confused) for the 4 studied PCB congeners in a) the Bay of Biscay and b) the Gulf of Lions. 


\section{Gulf of Lions}

a)

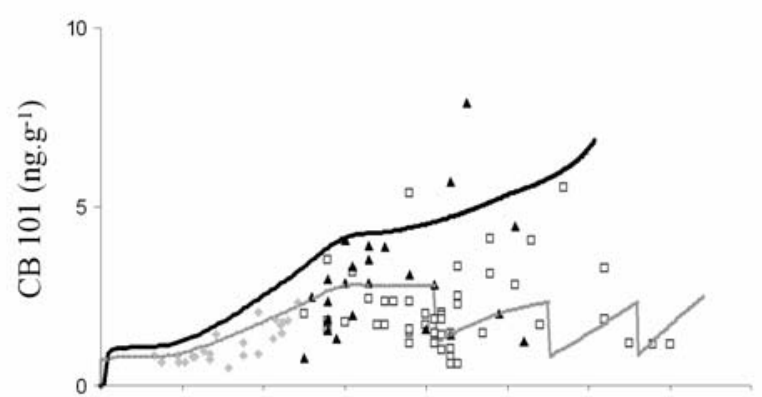

b)

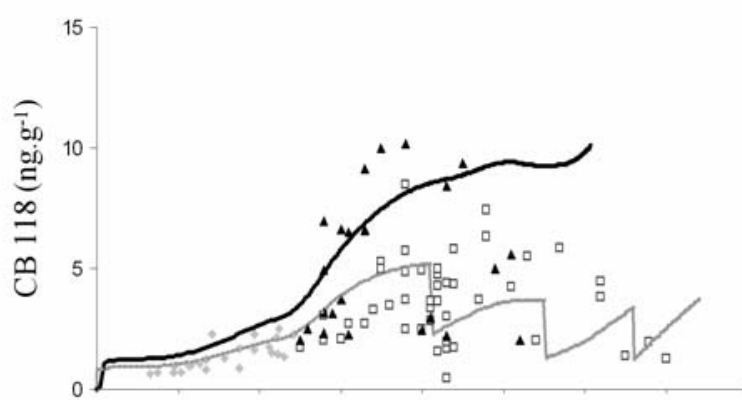

c)

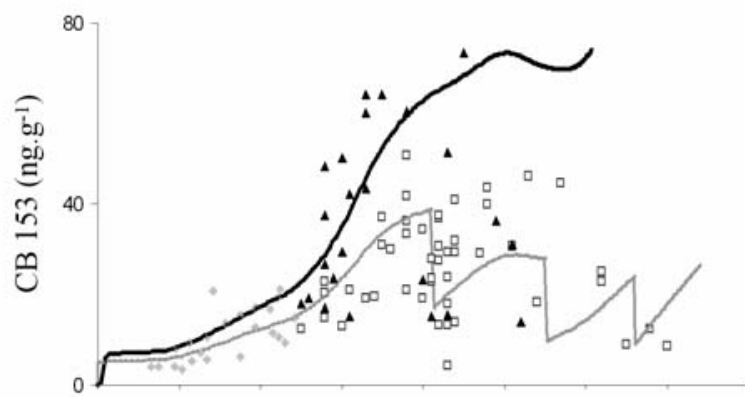

d)

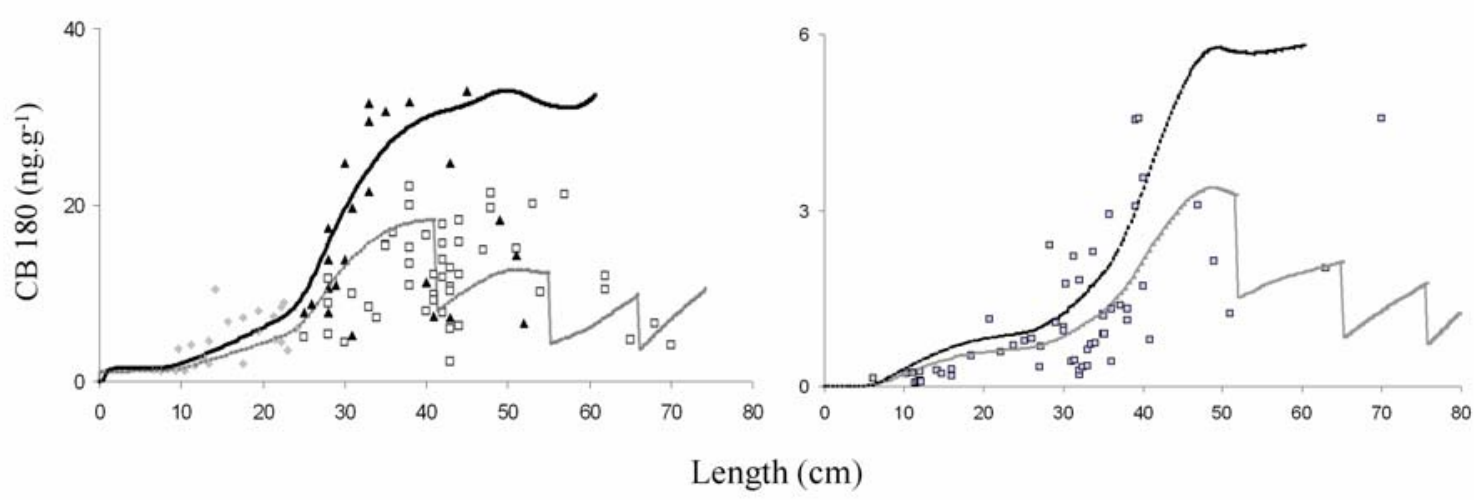

Bay of Biscay
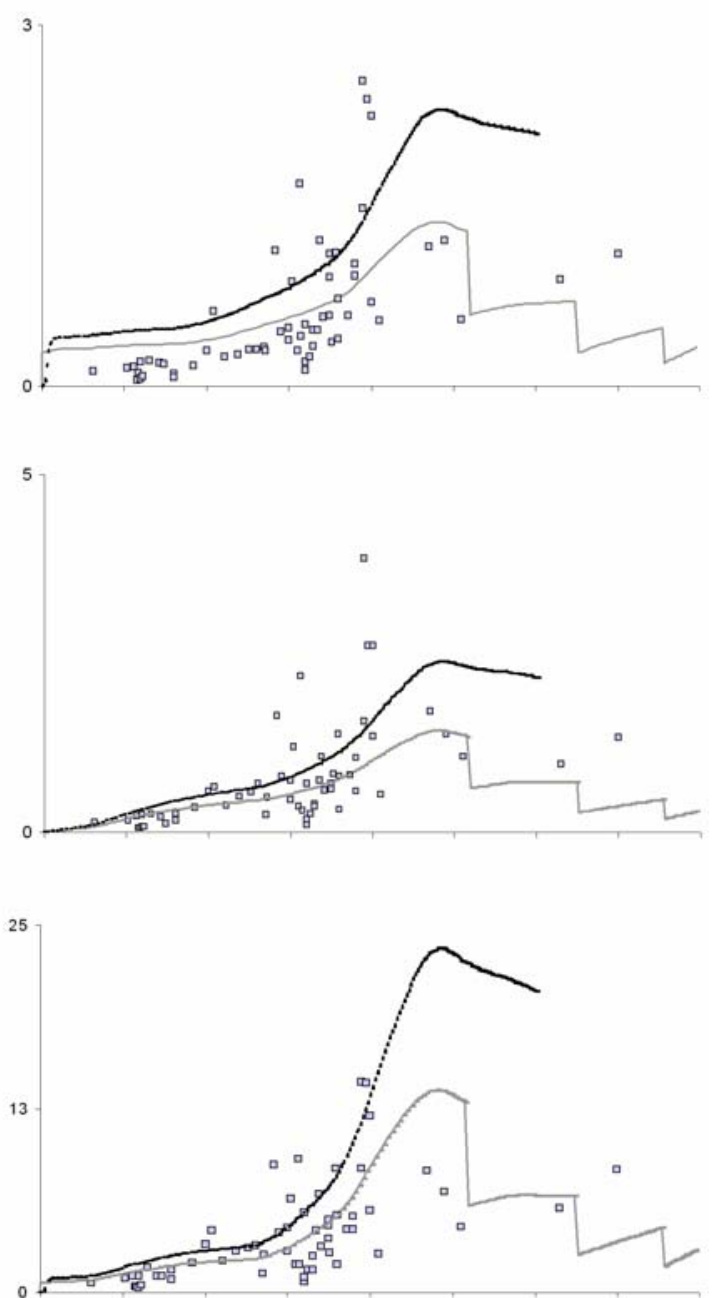

Figure 7: Simulated concentrations of PCBs $\left(\mathrm{ng} \mathrm{g}^{-1} \mathrm{~W}\right)$ as function of length for female (grey line) and male (black line) hake in the Gulf of Lions and the Bay of Biscay, for a period of 10 years. In the Gulf of Lions measured concentrations (symbols) distinguish undetermined sex hakes (light grey squares), females (white squares) and males (black triangles). 


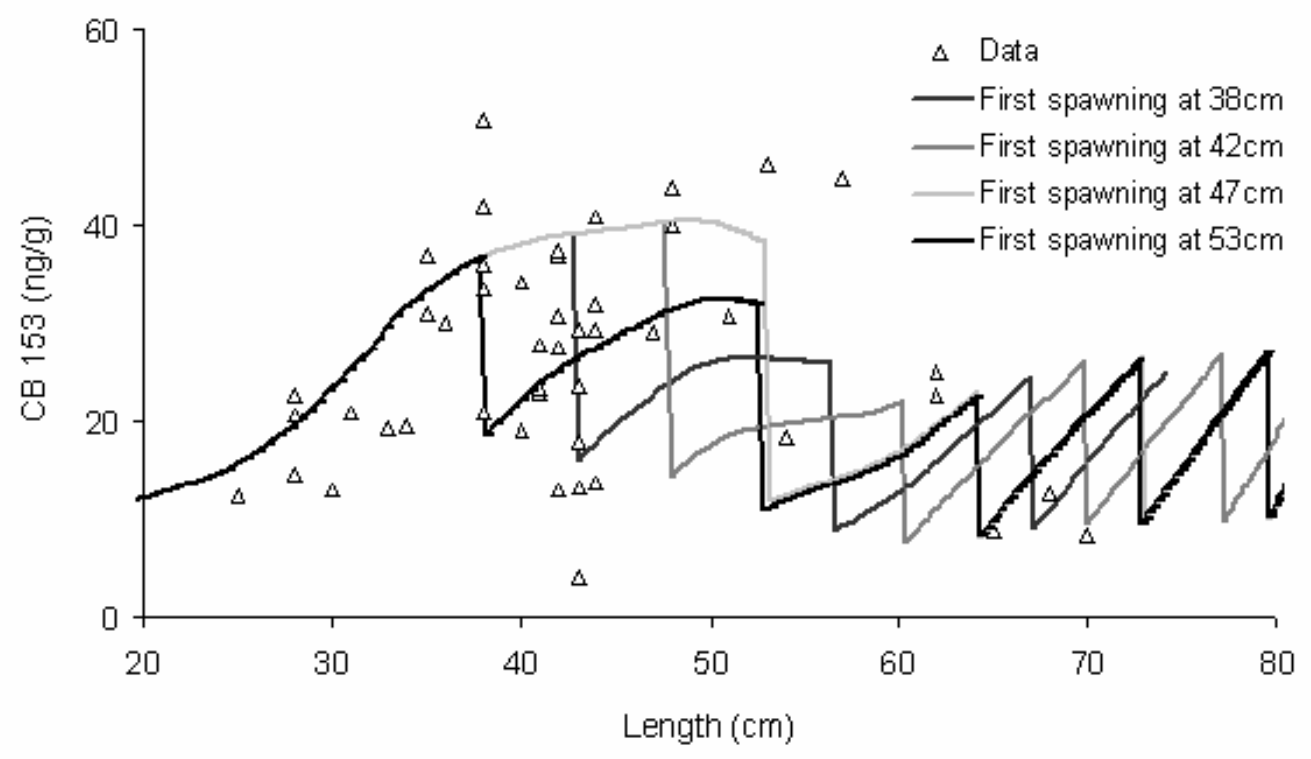

Figure 8: Simulations of the evolution of CB153 concentrations $\left(\mathrm{ng} \mathrm{g}^{-1} \mathrm{~W}\right)$ in females from the Gulf of Lions according to different size at first spawning (38,42, 47, and $53 \mathrm{~cm})$, for a period of 10 years. Data for female hakes in the Gulf of Lions are provided (black triangles).
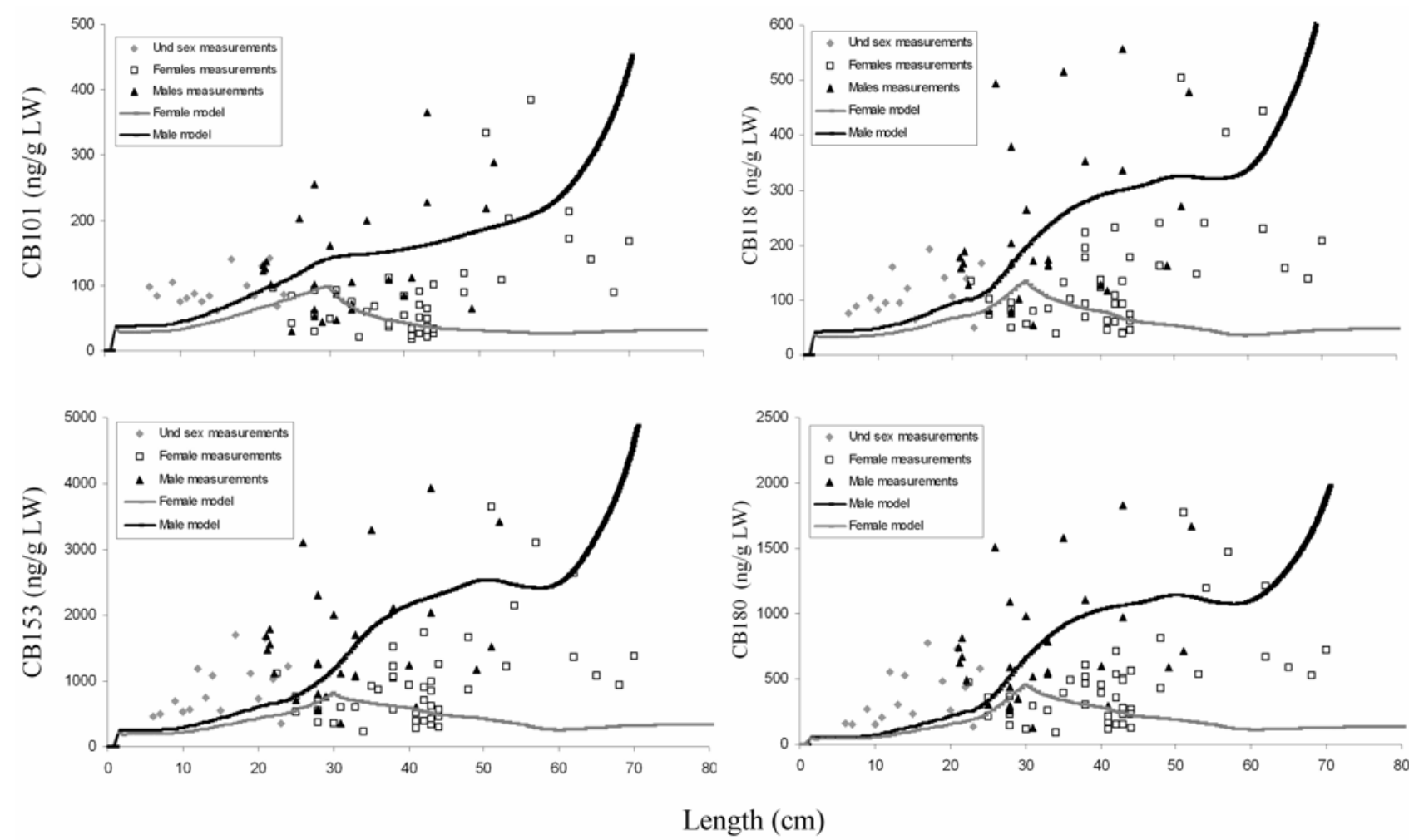
Figure 9: Simulated concentrations of lipid normalized PCBs (ng $\mathrm{g}^{-1} \mathrm{LW}$ ) as function of length for female (grey line) and male (black line) hake in the Gulf of Lions and the Bay of Biscay, for a period of 10 years. In the Gulf of Lions measured concentrations (symbols) distinguish undetermined sex hakes (grey squares), females (white squares) and males (black triangles).

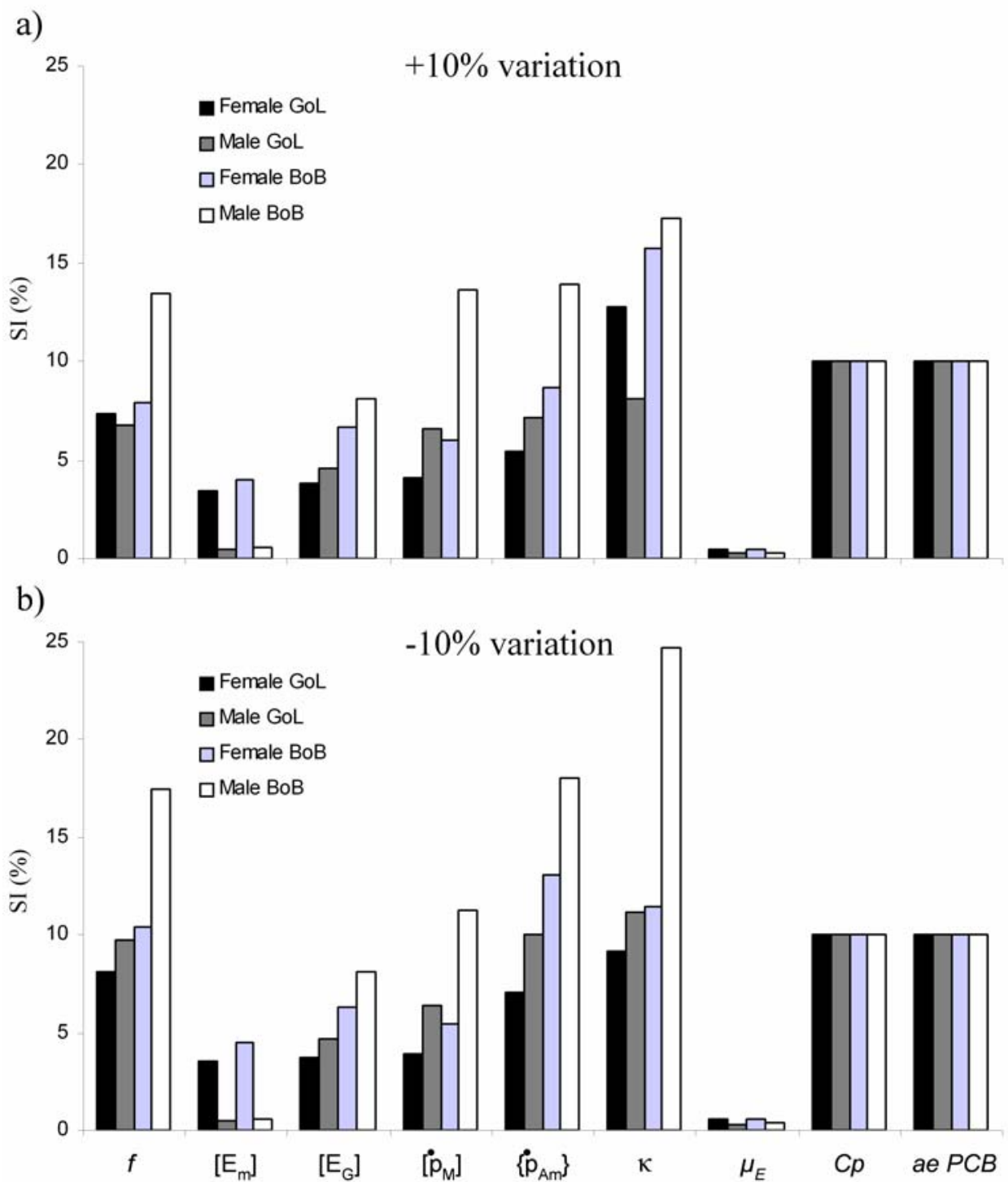

Figure 10: Sensitivity index $(S I)$ on total CB153 concentrations in hake, computed for both sexes in the Gulf of Lions (GoL) and the Bay of Biscay (BoB). a) effect of $+10 \%$ of parameter values, and $b$ ) effect of $-10 \%$ of parameter values. 